\title{
Portfolio Home Bias and External Habit Formation
}

\author{
Andreas Stathopoulos*
}

This version: November 17, 2011

\begin{abstract}
This paper explores international portfolio choice in a multi-country, multi-good general equilibrium setting which features time-varying risk aversion generated by external habit formation. It is shown that time variation in conditional risk aversion generates time variation in the countries' relative consumption expenditure. As a result, financing equilibrium consumption entails hedging against adverse fluctuations in risk aversion. In equilibrium, an increase in home risk aversion tends to appreciate the home equity and depreciate the foreign equity, so each agent hedges by shifting her equity portfolio towards the home equity claim. Furthermore, the model is able to generate realistic asset price and exchange rate dynamics, satisfying a long-standing need of the general equilibrium literature in international finance.

JEL classification: G11, G12, G15, F30.
\end{abstract}

Keywords: Portfolio home bias, habit formation, asset pricing.

${ }^{*}$ University of Southern California, Marshall School of Business, Los Angeles, CA 90089. Email: astathop@marshall.usc.edu. I am grateful to Geert Bekaert, Wayne Ferson and Tano Santos, as well as seminar participants at USC Marshall, for helpful comments. 


\section{Introduction}

In the absence of market frictions, the desire for international risk sharing should lead homogeneous investors across the world to hold the world market portfolio. However, one of the most extensively documented stylized facts in international finance is the overwhelming tendency of investors to hold equity portfolios heavily skewed towards assets of their home country. ${ }^{1}$ It has long been recognized that equity home bias is puzzling, as it suggests that investors forego significant international diversification benefits. ${ }^{2}$ Theoretical attempts to explain the equity home bias puzzle have been largely unsuccessful and, in some cases, have exacerbated the puzzle, suggesting that optimal equity portfolios should have a foreign bias. ${ }^{3}$

Specifically, the literature has proposed models that relax either the frictionless markets assumption or the homogeneous investors assumption, providing one of the following four explanations of equity home bias: i) it results from hedging against real exchange rate fluctuations, ii) it results from hedging against non-traded income shocks, iii) it is due to frictions in international financial markets (such as taxes and trading costs), and iv) it is due to asymmetric information or behavioral biases. Note that only the first explanation, hedging against adverse real exchange rate shocks, is consistent with both rationality and frictionless and complete financial markets, which is the benchmark assumption of the asset pricing literature. Since real exchange rates are the relative prices of the countries' consumption baskets, deviations from purchasing power parity - and, thus, non-trivial exchange rate behavior - presupposes heterogeneity in the countries' consumption patterns.

Typically, the aforementioned cross-country differences in consumption are the result of heterogeneous preferences or frictions in the international goods markets. Specifically, it is commonly assumed that agents' preferences are home biased or that there are frictions in the international trade for goods, in the form of either finite or infinite deadweight costs. In both cases, consumption is home biased in equilibrium. Agents use their portfolios in order to finance their consumption, so hedging against real exchange rate risk generates equity home bias if home equity performs better than foreign equity when the home consumption expenditure is high. In a general equilibrium setting, the behavior of equity returns and consumption expenditures depend on the agents' risk preferences and the elasticity of substitution among the various goods in the global economy. For example, if agents are sufficiently risk averse and, thus, value smooth consumption, consumption expenditure is high when the home good is relatively expensive, so hedging against real exchange rate risk entails holding assets that perform well in periods of home real exchange rate appreciation. The behavior of the home and foreign equity claims

\footnotetext{
${ }^{1}$ See French and Poterba (1991).

${ }^{2}$ There is a long literature on the importance and benefits of international diversification; see, for example, Grubel (1968), Levy and Sarnat (1970), Lessard (1973), Solnik (1974a) and Errunza (1983).

${ }^{3}$ Extensive reviews of the literature on the equity home bias puzzle are provided by Lewis (1999), Karolyi and Stulz (2003), Sercu and Vanpee (2007) and Coeurdacier and Rey (2011).
} 
depends, in turn, to the elasticity of substitution of the goods in which their dividends are paid.

A long literature has explored the conditions that would generate equity home bias under standard CRRA preferences and has shown that hedging against real exchange rate fluctuations are unable to generate sufficient portfolio home bias for reasonable parameter values. In the words of Coeurdacier and Rey (2011) "there is now a consensus that the hedging of real exchange rate risk cannot account empirically for the equity home bias". Furthermore, standard preferences cannot generate realistic asset pricing returns, a severe shortcoming for any model that purports to explain portfolio choice. Lewis (1999) notes that "[A] major problem with reconciling investor home bias with international consumption movements is that the volatility of the implicit intertemporal marginal rate of substitution is not high enough to explain stock price movements." 4 As a result, a large part of the literature has abandoned the quest to generate adequate equity home bias in an frictionless economy populated by rational investors and has focused to the other three explanations.

This paper aims to overturn this consensus by proposing a multi-country general equilibrium model that features equity home bias in the absence of any frictions not only in the international financial markets, but also in the international goods markets. The key assumption is external habit formation, which generates stochastically varying risk aversion. The key mechanism is novel: equity home bias results from the desire of investors to hedge against adverse shocks in their conditional risk aversion. I show that optimal risk sharing, under complete markets, implies a very high degree of equity home bias; in fact, equilibrium equity portfolios are superbiased towards the home asset, involving a superlong position in the home equity claim financed by shorting at least one of the foreign equity claims.

In more detail, I consider a multi-country general equilibrium model, in the tradition of Lucas (1982). The global economy comprises $n+1$ countries, one domestic and $n$ foreign, each populated by a representative agent. There are $n+1$ internationally tradeable goods, one domestic and $n$ foreign, and each agent is endowed with a claim on the entirety of the global endowment of the corresponding good. Agents' preferences are characterized by both home bias in preferences and external habit formation. Specifically, each agent has preferences over a home-biased Cobb-Douglas consumption basket on all $n+1$ goods. Following the asset pricing literature, each agent has a habit level of consumption that slowly adjusts to the consumption level, generating time variation in conditional risk aversion. As a result of international risk sharing, the equilibrium consumption expenditure of each country is increasing in the country's relative conditional risk aversion: more risk averse countries consume more, due to their higher marginal utility. As a result, to finance her consumption, each agent needs to hold a portfolio

\footnotetext{
${ }^{4}$ More forcefully, van Wincoop and Warnock (2010) show that, under CRRA preferences, home bias in assets cannot be linked to home bias in goods without generating unrealistic results about asset returns and exchange rates. Discussing a wider class of models, Coeurdacier and Rey (2011) note that while certain models "have some success in replicating some feautures of aggregate portfolio data, they cannot replicate realistic moments for asset prices and exchange rates".
} 
that has two components: the tangency portfolio of the instantaneous mean-variance frontier and a hedging portfolio that insures the agent against increases in her conditional risk aversion.

To determine whether the hedging demands of the agents can give rise to portfolio home bias, I adopt the simplest and most intuitive specification: the internationally tradeable assets are the claims on the endowments of the $n+1$ countries. An increase in a country's risk aversion has two opposing effects on the price of its equity claim: a valuation effect and a terms of trade (i.e. cash flow) effect. Ceteris paribus, an increase in home conditional risk aversion decreases the price-dividend ratio of the home equity, as would be the case in a closed economy (valuation effect), but increases the numeraire price of the home equity dividends (terms of trade effect). The terms of trade effect dominates the valuation effect, so an increase in home risk aversion tends to appreciate the home equity. Given that an increase in home risk aversion is associated by an increase in home consumption expenditure, home equity is a better hedge against home risk aversion shocks than foreign equity. Hence, hedging against real exchange rate risk entails holding a home biased portfolio. Furthermore, the model is able to generate realistic asset price and exchange rate dynamics, satisfying a long-standing need of the general equilibrium literature in international finance.

Both the equity home bias and the empirically plausible asset price and exchange rate behavior are due to external habit formation. In its absence, i.e. with log utility agents, home bias in preferences is able to generate home bias in consumption, but not in equity portfolios. The reason is that the relative consumption expenditure of each country is constant: fluctuations in relative endowments cause inverse fluctuations in the relative price of the goods and the desire of the agents to smooth their consumption is exactly offset by their desire to consume when their consumption basket is cheap. As a result, equilibrium consumption expenditure can be financed by holding appropriate shares of the world market portfolio. ${ }^{5}$

This paper is part of the long literature on portfolio home bias and, specifically, of the strand that focuses on hedging against real exchange rate risk. Solnik (1974b), Sercu (1980), Stulz (1981b) and Adler and Dumas (1983) focus on hedging against inflation risk. However, Adler and Dumas (1983) show that inflation hedging portfolios are almost entirely composed of home bonds, since risk averse agents prefer to assume some small inflation risk rather than hold more substantial exchange rate risk, while Cooper and Kaplanis (1994) show that the data strongly reject the claim that portfolio home bias can be explained by hedging for inflation risk. In a general equilibrium framework, Cole and Obstfeld (1991), Zapatero (1995), Kollman (2006b) and Pavlova and Rigobon (2007) generate real exchange rate fluctuations by adopting home biased preferences, while Stockman and Dellas (1989) and Baxter, Jermann and King

\footnotetext{
${ }^{5}$ Furthermore, if the goods have unit elasticity of substitution, fluctuations in the relative endowment are exactly offset by fluctuations in the relative prices of the goods. As a result, if the internationally traded assets are the claims to the countries' endowment, their dividends are perfectly correlated, equilibrium portfolios are indeterminate. Zapatero (1995) illustrates that point in a two-good, two country model.
} 
(1998) consider non-tradeable goods. ${ }^{6}$ Uppal (1993) departs from the assumption of outright non-tradeability and considers finite trade costs. ${ }^{7}$

Regarding hedging against non-traded income shocks, Baxter and Jermann (1997) argue that domestic human capital returns are highly correlated with domestic equity returns and, thus, investors should hold foreign biased equity portfolios. ${ }^{8}$ However, Heathcote and Perri (2008), Coeurdacier and Gourinchas (2009) and Coeurdacier, Kollman and Martin (2010) show that, in the presence of internationally tradeable bonds, equities are valuable as hedges of non-traded income risk. Tesar (1993) and Pesenti and van Wincoop (2002) consider partial equilibrium portfolio choice in economies in which claims on non-tradeable goods are themselves non-tradeable. Tesar (1993) argues that, under those assumptions, home bias in the shares of claims on tradeable goods is possible, but Pesenti and van Wincoop (2002) show that the degree of home bias generated in such an economy would be insufficient to account for the bias observed in the data.

Models that examine asset market frictions associated with international portfolio choice typically focus on taxes, trading costs and investment restrictions and argue that frictions may be high enough to wipe out almost all gains from international diversification. ${ }^{9}$ Other models emphasize informational or behavioral explanations: domestic and foreign investors differ in either their information or their beliefs about the distribution of asset returns and those differences are such that tilt their portfolios towards their home assets. ${ }^{10}$

This paper also belongs to the recent literature that embeds complex preferences in general equilibrium open economy models, thus bridging the asset pricing literature with the international finance literature. ${ }^{11}$ That literature has not focused on equilibrium international portfolios, with the exception of Shore and White (2006), which address the portfolio home bias puzzle with a model that incorporates external habit formation. In their model, portfolio home bias results from the attempt of unconstrained investors to mimic, in a "catching up with the

\footnotetext{
${ }^{6}$ In the same vein, Serrat (2001) proposes a model with heterogeneous preferences and non-tradeables, but Kollman (2006a) shows the only aspect of portfolio choice that can be pinned down is each agent holds an internationally diversified portfolio of claims on tradeable goods.

${ }^{7} \mathrm{He}$ shows that, for realistic levels of risk aversion, the model generates foreign, rather than home, equity bias. Coeurdacier (2009) confirms that, for reasonable trade costs, optimal portfolios exhibit foreign bias. The importance of trade costs is also highlighted in Obstfeld and Rogoff (2000).

${ }^{8}$ Julliard (2002) argues that Baxter and Jermann (1997) overstate the advantage of foreign equity over domestic equity for hedging domestic labor income risk, so considering human capital does not necessarily worsen the home bias puzzle.

${ }^{9}$ Black (1974) considers the effects of taxation of net foreign investment, while Stulz (1981a) focuses on taxes on gross foreign investment. Cooper and Kaplanis (1994) propose a model that incorporates deadweight costs of foreign investment and show that the level of deadweight costs that is needed to justify the empirical levels of portfolio home bias is implausibly high. Tesar and Werner (1995) show that foreign equity investments have much higher turnover rates than domestic equity investments, so international transaction costs are unlikely to explain the lack of sufficient international portfolio diversification.

${ }^{10}$ Notable papers include French and Poterba (1991), Kang and Stulz (1997), Brennan and Cao (1997), van Nieuwerburgh and Veldkamp (2008) and Dumas, Lewis and Osambela (2011).

${ }^{11}$ See, for example, Bekaert (1996), Lustig and Verdelhan (2007), Moore and Roche (2006), Aydemir (2008), Farhi and Gabaix (2008), Verdelhan (2010), Bansal and Shaliastovich (2010), Colacito and Croce (2010a, 2010b).
} 
Joneses" spirit, the portfolio behavior of small entrepreneurs, who are forced to hold domestic equity for agency reasons.

The rest of the paper is organized as follows. Section 2 presents the setup of the model, while Section 3 describes the properties of equilibrium prices and quantities. Section 4 examines the connection between hedging against changes in conditional risk aversion and portfolio home bias. Section 5 concludes. The Appendix contains the proofs and all supplementary material not included in the main body of the paper.

\section{The model}

\section{$2.1 \quad$ Endowments}

The world economy comprises $n+1$ countries, indexed by $i$ : the Domestic country $(i=0)$ and $n$ foreign countries $(i=1, \ldots, n)$, each of which is populated by a single risk-averse representative agent. There are $n+1$ distinct perishable goods in the world economy, indexed by $j$ : the domestic good $(j=0)$ and $n$ foreign goods $(j=1, \ldots, n)$. Uncertainty in the economy is represented by a filtered probability space $(\Omega, \mathcal{F}, \mathbf{F}, P)$, where $\mathbf{F}=\left\{\mathcal{F}_{t}\right\}$ is the filtration generated by the standard $m$-dimensional Brownian motion $\mathbf{B}_{t}, t \in[0, \infty)$, augmented by the null sets. All the stochastic processes introduced in the remainder of this paper are assumed to be progressively measurable with respect to $\mathbf{F}$ and to satisfy all the necessary regularity conditions for them to be well-defined. All (in)equalities that involve random variables hold $P$-almost surely.

Each agent $i$ is initially endowed with a claim on the entirety of the world endowment of the corresponding good $(j=i)$. The endowment stream of good $j$ is denoted by $\left\{\widetilde{X}_{t}^{j}\right\}$; all endowment processes are Itô processes satisfying:

$$
d \log \widetilde{X}_{t}^{j}=\mu_{t}^{j, X} d t+\boldsymbol{\sigma}_{t}^{j, X \prime} \mathbf{d B}_{t}, j=0,1, \ldots, n
$$

with $\boldsymbol{\sigma}_{t}^{j, X} \neq \mathbf{0}$ for all $j$. All goods are frictionlessly traded internationally, so the price of each good, in units of the numeraire, is the same in all countries. Without loss of generality, the numeraire good is the domestic good, so its price is $Q_{t}^{0} \equiv 1, \forall t \in[0, \infty)$. The numeraire price of each foreign good is denoted by $Q_{t}^{j}{ }^{12}$

\subsection{Assets}

All agents' endowments lie in the asset span, so the world economy is a securities market economy. Agents can frictionlessly trade $m+1$ non-redundant securities; of those, $m$ are risky and 1 is locally riskless in terms of the numeraire. The risky asset returns, in units of the numeraire

\footnotetext{
${ }^{12}$ Stathopoulos (2011) shows that a two-country, two-good version of this model can address the Brandt, Cochrane and Santa-Clara (2006) international risk sharing puzzle.
} 
good, are given by the $m$-dimensional process

$$
\mathbf{d R}_{t}=\boldsymbol{\mu}_{t} d t+\boldsymbol{\sigma}_{t} \mathbf{d B}_{t}
$$

where $\boldsymbol{\mu}_{t}$ is the $m \times 1$ vector of expected returns and $\boldsymbol{\sigma}_{t}$ is the $m \times m$ asset return diffusion matrix. Since the assets are non-redundant, $\sigma_{t}$ is a non-singular matrix and securities markets are dynamically complete. Some of the risky assets may be in zero net supply, with the rest in positive net supply. Since the world economy is a securities market economy, the aggregate dividend of the risky assets equals the world endowment for each good and each period.

The locally riskless asset is in zero net supply and its price, in units of the numeraire, is denoted by $D_{t}$ and satisfies

$$
d D_{t}=r_{t}^{f} D_{t} d t
$$

where $r_{t}^{f}$ is the continuously compounded numeraire riskless rate. Then, we can define excess returns as

$$
\mathbf{d R}_{t}^{e}=\boldsymbol{\mu}_{t}^{e} d t+\boldsymbol{\sigma}_{t} \mathbf{d B}_{t}
$$

where $\boldsymbol{\mu}_{t}^{e}=\boldsymbol{\mu}_{t}-r_{t}^{f} \mathbf{1}$, with $\mathbf{1}$ representing a $m \times 1$ vector of ones.

\subsection{Preferences}

Representative agent $i$ has expected discounted utility

$$
E_{0}\left[\int_{0}^{\infty} e^{-\rho t} u^{i}\left(X_{t}^{i, 0}, X_{t}^{i, 1}, \ldots, X_{t}^{i, n}\right) d t\right]
$$

where $\rho>0$ is her subjective discount rate, and her instantaneous utility function is

$$
u^{i}\left(X_{t}^{i, 0}, X_{t}^{i, 1}, \ldots, X_{t}^{i, n}\right)=\log \left(\left(\prod_{j=0}^{n}\left(X_{t}^{i, j}\right)^{a^{i, j}}\right)-H_{t}^{i}\right)=\log \left(C_{t}^{i}-H_{t}^{i}\right)
$$

where $X_{t}^{i, j}$ is the quantity of good $j$ that agent $i$ consumes at time $t, C^{i} \equiv\left(\prod_{j=0}^{n}\left(X^{i, j}\right)^{a^{i, j}}\right)$ is the domestic consumption basket and $H^{i}$ is the habit level associated with that consumption basket. Notably, preferences are not symmetric regarding goods; the preferences of agent $i$ towards the $n+1$ goods are described by the vector of preference parameters $\mathbf{a}^{i}=\left[a^{i, 0}, a^{i, 1}, \ldots, a^{1, n}\right]$, such that $\sum_{j=0}^{n} a^{i, j}=1$ and $a^{i, j}>0$ for all $i$ and $j$. We also define the $(n+1) \times(n+1)$ preference matrix $\mathbf{A}=\left[a_{i, j}\right]=a^{i-1, j-1}$. By construction, $\mathbf{A}$ is a row stochastic matrix.

The external habit is of the Menzly, Santos and Veronesi (2004) form. Specifically, the 
inverse surplus consumption ratio $G^{i}=\left(\frac{C^{i}-H^{i}}{C^{i}}\right)^{-1}$ solves the stochastic differential equation

$$
d G_{t}^{i}=\varphi\left(\bar{G}-G_{t}^{i}\right) d t-\delta\left(G_{t}^{i}-l\right)\left(\frac{d C_{t}^{i}}{C_{t}^{i}}-E_{t}\left(\frac{d C_{t}^{i}}{C_{t}^{i}}\right)\right)
$$

The inverse surplus consumption ratio is a mean-reverting process, reverting to its long-run mean of $\bar{G}$ at speed $\varphi$ and is driven by consumption growth shocks. The parameter $\delta>0$ scales the impact of a consumption growth shock and the parameter $l \geq 1$ is the lower bound of the inverse surplus ratio $G_{t}$. Obviously, $\bar{G}>l$. The local curvature of the utility function is $-\frac{u_{C C}\left(C_{t}^{i}, H_{t}^{i}\right)}{u_{C}\left(C_{t}^{i}, H_{t}^{i}\right)} C_{t}^{i}=G_{t}^{i}$; for that reason, in a slight abuse of terminology, in the remainder of this article $G^{i}$ will be sometimes referred to as the risk aversion of country $i{ }^{13}$ Importantly, note that country heterogeneity in the composition of the consumption basket (i.e. differences in the rows of $\mathbf{A}$ ) induce heterogeneity in the consumption shocks and, thus, in the level of conditional risk aversion across countries.

Lastly, we adopt the notation $\boldsymbol{\sigma}_{t}^{i, G}$ for the diffusion term of $\frac{d G_{t}^{i}}{G_{t}^{i}}$ :

$$
\boldsymbol{\sigma}_{t}^{i, G \prime} \mathbf{d B}_{t} \equiv-\delta\left(\frac{G_{t}^{i}-l}{G_{t}^{i}}\right)\left(\frac{d C_{t}^{i}}{C_{t}^{i}}-E_{t}\left(\frac{d C_{t}^{i}}{C_{t}^{i}}\right)\right)
$$

\subsection{Prices and real exchange rates}

The time $t$ price of country $i$ consumption basket $C^{i}$, in units of the numeraire good, is denoted by $P^{i}$ and satisfies

$$
P_{t}^{i}=\prod_{j=0}^{n}\left(\frac{Q_{t}^{j}}{a^{i, j}}\right)^{a^{i, j}}
$$

and is defined as the minimum expenditure required to buy a unit of the consumption basket $C^{i}$.

The real exchange rate of foreign country $i$ against the domestic country, which expresses the price of a unit of the foreign consumption basket in units of the domestic consumption basket, is:

$$
E_{t}^{i}=\frac{P_{t}^{i}}{P_{t}^{0}}=\frac{\prod_{j=0}^{n}\left(\frac{Q_{t}^{j}}{a^{i, j}}\right)^{a^{i, j}}}{\prod_{j=0}^{n}\left(\frac{Q_{t}^{j}}{a^{0, j}}\right)^{a^{0, j}}}=\prod_{j=0}^{n}\left(\frac{\left(a^{0, j}\right)^{0 . j}}{\left(a^{i, j}\right)^{i, j}}\right) \prod_{j=0}^{n}\left(Q_{t}^{j}\right)^{a^{i, j}-a^{0, j}}
$$

The real exchange rate of country $i$ is constant and equal to 1 (purchasing power parity) only

\footnotetext{
${ }^{13}$ One of the differences of the two models is that, while Campbell and Cochrane (1999) model the surplus consumption ratio, Menzly, Santos and Veronesi (2004) model the inverse surplus consumpion ratio. Buraschi and Jiltsov (2007), Santos and Veronesi (2006) and Bekaert, Engstrom and Xing (2009) also model the inverse surplus consumption ratio.
} 
if the two countries' preferences are identical $\left(a^{i, j}=a^{0, j}\right.$ for all goods $\left.j\right)$, so that the two consumption baskets have the same composition. In the case of differences in preferences, purchasing power parity is violated, so the two agents face different investment opportunity sets in real terms.

\subsection{The agents' problem}

Let the $m x 1$ vector $\boldsymbol{\pi}_{t}^{i}$ describe the investment decision of agent $i$, which each element of the vector describing the amount, in units of the numeraire, that agent $i$ invests in each risky asset in period $t$. Thus, agent $i$ chooses consumption shares $X_{t}^{i, j}$ and amounts $\boldsymbol{\pi}_{t}^{i}$ so as to maximize her expected discounted utility

$$
\max _{\left\{X_{t}^{i, j}, \pi_{t}^{i}\right\}} E_{0}\left[\int_{0}^{\infty} e^{-\rho t} \log \left(C_{t}^{i}-H_{t}^{i}\right) d t\right]
$$

subject to the intertemporal flow budget constraint:

$$
d W_{t}^{i}=\boldsymbol{\pi}_{t}^{i \prime}\left(\boldsymbol{\mu}_{t}^{e} d t+\boldsymbol{\sigma}_{t} \mathbf{d B}_{t}\right)+W_{t}^{i} r_{t}^{f} d t-C_{t}^{i} P_{t}^{i} d t
$$

where $W_{t}^{i}$ is the period $t$ wealth of agent $i$ in units of the numeraire; consequently, the investment of agent $i$ in the locally riskless asset is $W_{t}^{i}-\boldsymbol{\pi}_{t}^{i \prime} \mathbf{1}$. If $W_{t}^{i} \neq 0$, we can also define the country $i$ portfolio weight vector $\mathbf{x}_{t}^{i}$; it denotes the share of each risky asset in the risky portfolio of country $i$ and is given by $\mathbf{x}_{t}^{i}=\frac{1}{W_{t}^{i}} \boldsymbol{\pi}_{t}^{i}$. The portfolio weight of the riskless asset is, thus, $1-\mathbf{x}_{t}^{i \prime} \mathbf{1}$.

\section{Equilibrium}

Under the assumption of effective market completeness, there is a unique numeraire state-price density, $\Xi$, in the world economy. The intertemporal budget constraint of agent $i$ can be written in static form as follows:

$$
E_{0}\left[\int_{0}^{\infty} \frac{\Xi_{t}}{\Xi_{0}} C_{t}^{i} P_{t}^{i} d t\right] \leq E_{0}\left[\int_{0}^{\infty} \frac{\Xi_{t}}{\Xi_{0}} \tilde{X}_{t}^{i} Q_{t}^{i} d t\right]
$$

This is nothing but the familiar restriction that the present value of domestic consumption cannot exceed the present value of the domestic endowment. The global numeraire state-price density $\Xi$ has to price all the available assets, so it has satisfy the SDE

$$
\frac{d \Xi_{t}}{\Xi_{t}}=-r_{t}^{f} d t-\boldsymbol{\eta}_{t}^{\prime} \mathbf{d} \mathbf{B}_{t}
$$

where $\boldsymbol{\eta}_{t}=\boldsymbol{\sigma}_{t}^{-1} \boldsymbol{\mu}_{t}^{e}$ is the market price of risk process. After replacing each agent's intertemporal dynamic budget constraint with her static budget constraint, we can solve for the competitive 
equilibrium; the solution details can be found in the Appendix.

\subsection{Macroeconomic quantities and prices}

The equilibrium consumption allocation is

$$
X_{t}^{i, j}=\frac{a^{i, j} \lambda^{i} G_{t}^{i}}{\sum_{k=0}^{n} a^{k, j} \lambda^{k} G_{t}^{k}} \tilde{X}_{t}^{j}
$$

or, introducing the share functions

$$
\omega_{t}^{i, j}: \omega_{t}^{i, j}=\frac{a^{i, j} \lambda^{i} G_{t}^{i}}{g_{t}^{j}}
$$

with $\omega_{t}^{i, j}$ being the proportion of good $j$ consumed in country $i$ and $g_{t}^{j}$ being the effective conditional risk aversion of the demand for good $j$, defined as

$$
g_{t}^{j} \equiv \sum_{k=0}^{n} a^{k, j} \lambda^{k} G_{t}^{k}
$$

Note that $g_{t}^{j}$ is a linear combination of all countries' conditional risk aversion, weighted by the strength of each country's preference for good $j$ : the product of the preference of each country for good $j\left(a^{k, j}\right)$ and the welfare weight of that country $\left(\lambda^{j}\right)$. For future use, we also define the unconditional mean of the effective risk aversion for good $j, \bar{g}^{j}$, as:

$$
\bar{g}^{j} \equiv \sum_{k=0}^{n} a^{k, j} \lambda^{k} \bar{G}
$$

Consumption shares reflect preferences in two ways. First, each country's share of all goods' endowment is increasing in its own risk aversion and decreasing in all other countries' risk aversion. In other words, an increase in a given country's risk aversion relative to the risk aversion of its trade partners increases its consumption share for all goods. This is due to risk sharing: when a country is in a worse state of the world compared to its trading partners and its risk aversion is relatively high, it needs to consume more, as its marginal utility of consumption is higher, so tradeable goods consumption adjusts in order for countries to efficiently share risk. Second, the significance of the risk aversion of different countries regarding consumption allocation depends on the preference parameter matrix A. Specifically, the consumption share that country $i$ receives of good $j\left(\omega_{t}^{i, j}\right)$ is dependent on the strength of the preference of country $i$ for good $j$ relative to the preference of all other countries for good $j: \omega_{t}^{i, j}$ is increasing in $a^{i, j}$ and decreasing in $a^{i^{\prime}, j}$ for $i^{\prime} \neq i$. Thus, in equilibrium, home bias in preferences generates home 
bias in consumption.

The numeraire price of foreign good $j$ is

$$
Q_{t}^{j}=\frac{g_{t}^{j}}{g_{t}^{0}} \frac{\widetilde{X}_{t}^{0}}{\widetilde{X}_{t}^{j}}
$$

and depends on the scarcity of good $j$ relative to the numeraire good, as well as the effective risk aversion of the demand for good $j$ relative to that for the numeraire good. High effective risk aversion regarding good $j$ indicates increased marginal utility (and, thus, demand) for good $j$ and, thus, a higher numeraire price for good $j$.

The consumption expenditure in each country reflects risk sharing. Consider the share of global consumption expenditure that corresponds to country $i, \omega_{t}^{C, i}$ :

$$
\omega_{t}^{C, i} \equiv \frac{C_{t}^{i} P_{t}^{i}}{\sum_{k=0}^{n} C_{t}^{k} P_{t}^{k}}=\frac{\lambda^{i} G_{t}^{i}}{\sum_{k=0}^{n} \lambda^{k} G_{t}^{k}}
$$

Note that $\omega_{t}^{C, i}$ is independent of the preference matrix $\mathbf{A}$; only country conditional risk aversions matter. In effect, heterogeneous preferences matter because they induce different consumption shocks across countries, which, under the external habit formation mechanism, lead to crosscountry heterogeneity in risk aversion. The consumption expenditure share $\omega_{t}^{C, i}$ is increasing in country $i$ risk aversion and decreasing in all other countries' risk aversion. This is due to international risk sharing: since all countries have access to complete financial markets, they are able to risk share by, at each period, transferring consumption from the countries that need them the least (i.e. low risk aversion, low marginal utility countries) to countries that need them the most (high risk aversion, high marginal utility countries).

To finance its equilibrium consumption, country $i$ needs to adopt a trading strategy that pays the necessary resources in each state of the world. The share of global wealth that country $i$ needs to hold, $\omega_{t}^{W, i}$ is:

$$
\omega_{t}^{W, i} \equiv \frac{W_{t}^{i}}{\sum_{k=0}^{n} W_{t}^{k}}=\frac{\lambda^{i}\left(\rho G_{t}^{i}+\varphi \bar{G}\right)}{\sum_{k=0}^{n} \lambda^{k}\left(\rho G_{t}^{k}+\varphi \bar{G}\right)}
$$

Similarly to the consumption expenditure share $\omega_{t}^{C, i}$, the wealth share $\omega_{t}^{W, i}$ does not depend on the preference matrix $\mathbf{A}$ and is increasing in $G_{t}^{i}$ and decreasing in all $G_{t}^{i^{\prime}}, i^{\prime} \neq i$. Note that the wealth share $\omega_{t}^{W, i}$ is less sensitive than the consumption expenditure share $\omega_{t}^{C, i}$ to risk aversion fluctuations: changes in the consumption expenditure move in the same direction with changes in the wealth that finances said consumption, but their magnitude is smaller. As a result, the 
wealth-consumption ratio is time-varying:

$$
\frac{W_{t}^{i}}{C_{t}^{i} P_{t}^{i}}=\frac{1}{\rho} \frac{\rho G_{t}^{i}+\varphi \bar{G}}{(\rho+\varphi) G_{t}^{i}}
$$

is decreasing in its risk aversion $G_{t}^{i}$. Its steady-state value is $\frac{1}{\rho}$, as in the no habit case, and its limit when $G_{t}^{i}$ is approaching infinity is $\frac{1}{\rho+\varphi}<\frac{1}{\rho}$. Ceteris paribus, an increase in the conditional risk aversion $G_{t}^{i}$ entails an increase in the consumption expenditure share $\omega_{t}^{C, i}$, as a result of international risk sharing, and a smaller increase in the wealth share $\omega_{t}^{W, i}$, due to the decrease of the wealth-consumption ratio of country $i$.

The wealth share increases less than one-to-one with the consumption expenditure share due to the mean reversion of conditional risk aversion. As mentioned above, country $i$ wealth needs to finance future consumption, so $W_{t}^{i}$ equals the present value of future consumption expenditure:

$$
W_{t}^{i}=E_{t}\left[\int_{t}^{\infty} \frac{\Xi_{s}}{\Xi_{t}} C_{s}^{i} P_{s}^{i} d s\right]
$$

An increase in current risk aversion $G_{t}^{i}$ increases the current consumption expenditure share $\omega_{t}^{C, i}$ and, due to the persistence of the risk aversion process, also increases future expenditure shares $\omega_{s}^{C, i}, s>t$. However, due to the mean reversion property of $G_{t}^{i}$, the increase in each of the future consumption expenditure shares is a decreasing function of the intervening time $s-t$. The higher the mean reversion speed of the risk aversion process (higher $\varphi$ ), the less the wealth share needs to adjust to changes in the consumption expenditure share.

\subsection{Portfolios}

The question that remains to be answered is what kind of trading strategies do countries need to adopt in order to finance the aforementioned consumption allocations. The following proposition shows that each agent's equilibrium portfolio has two components: a conditionally mean-variance efficient portfolio, common for both agents, and a hedging portfolio, which differs across countries due to their differing preferences.

Proposition 1 The equilibrium portfolio of country $i$ satisfies

$$
\mathbf{x}_{t}^{i}=\left(\boldsymbol{\sigma}_{t} \boldsymbol{\sigma}_{t}^{\prime}\right)^{-1} \boldsymbol{\mu}_{t}^{e}+\left(\frac{\rho G_{t}^{i}}{\rho G_{t}^{i}+\varphi \bar{G}}\right)\left(\boldsymbol{\sigma}_{t}^{\prime}\right)^{-1}\left(\boldsymbol{\sigma}_{t}^{i, G}\right)
$$

The first, common, component of equilibrium country portfolios is the tangency portfolio of the instantaneous mean-variance frontier, $\left(\boldsymbol{\sigma}_{t} \boldsymbol{\sigma}_{t}^{\prime}\right)^{-1} \boldsymbol{\mu}_{t}^{e}$. Hedging portfolios are country-specific and hedge against changes in the country's risk aversion. Specifically, the hedging portfolio of country $i$ is the projection of country $i$ conditional risk aversion shocks to the asset span and, 
thus, is maximally conditionally correlated with shocks in conditional risk aversion $G_{t}^{i}$. It follows that the hedging portfolio of country $i$ provides the maximum possible insurance against changes in $G_{t}^{i}$. Therefore, external habit formation introduces a novel, and potentially quantitatively important, source of variation of equilibrium portfolios across countries.

The need to hedge against risk aversion fluctuations is a direct result of risk sharing. Recall that each country's consumption expenditure is increasing in its risk aversion and decreasing in the risk aversion of all its trading partners; when a country's conditional risk aversion is high, the country needs more resources to finance its equilibrium consumption allocation and, thus, it will adopt a trading strategy that delivers high resources at those times.

Note that the weight of the hedging portfolio in the optimal portfolio is

$$
\frac{\frac{\rho G_{t}^{i}}{\rho G_{t}^{i}+\varphi \bar{G}}}{1+\frac{\rho G_{t}^{i}}{\rho G_{t}^{i}+\varphi \bar{G}}}
$$

and, thus, is increasing in risk aversion $G_{t}^{i}$ : the more risk averse each agent is, the more she tilts her portfolio towards hedging further increases in her conditional risk aversion. When $G^{i}$ approaches infinity, the weight of the hedging portfolio approaches 0.5 , so mean-variance efficiency and the hedging motive become equally important.

In the absence of external habit formation (and, thus, time variation in conditional risk aversion), hedging demands are absent and each country holds only the conditional mean-variance optimal portfolio, so the standard international CAPM holds, irrespective of the preference matrix A, i.e. even in the presence of preference home bias. This is due to the consumption patterns that prevail in equilibrium: each country consumes a fixed proportion of each good, consumption expenditure is perfectly correlated across countries: the consumption expenditure shares and, thus, the wealth shares are constant and equal to the proportional welfare weight of each country:

$$
\omega_{t}^{C, i}=\omega_{t}^{W, i}=\frac{\lambda^{i}}{\sum_{k=0}^{n} \lambda^{k}}
$$

Since perfectly correlated consumption changes are financed by perfectly correlated wealth changes, the portfolio allocation that generates the desired wealth allocation across countries is one of perfect pooling. Thus, although preference home bias is able to generate consumption home bias, it is unable to generate portfolio home bias.

\subsection{The pricing of risk}

The following proposition expresses the risk premium of any asset in the form of an Intertemporal CAPM. 
Proposition 2 The expected excess return of any asset s satisfies

$$
E_{t}\left(d R_{t}^{s, e}\right)=\operatorname{cov}_{t}\left(d R_{t}^{s, e}, \frac{d W_{t}^{A}}{W_{t}^{A}}\right)-\sum_{i=0}^{n}\left(\frac{\lambda^{i} \rho G_{t}^{i}}{\sum_{k=0}^{n} \lambda^{k}\left(\rho G_{t}^{k}+\varphi \bar{G}\right)}\right) \operatorname{cov}_{t}\left(d R_{t}^{s, e}, \frac{d G_{t}^{i}}{G_{t}^{i}}\right)
$$

where $W_{t}^{A} \equiv \sum_{k=0}^{n} W_{t}^{k}$ is aggregate global wealth.

External habit formation introduces $n+1$ additional state variables, the country risk aversions $G^{i}, i=0,1, \ldots, n$, so risk premiums are compensation for covariance risk not only with aggregate global wealth (as in the standard international CAPM), but also with each of the country conditional risk aversion. Note that positive covariance with any country risk aversion $G^{i}$ generates a negative risk premium, as it indicates that the asset can be used to hedge against increases in $G^{i}$.

\section{Risk aversion hedging and portfolio home bias}

The previous section demonstrated that, given market completeness, country equilibrium portfolios may differ due to differing risk aversion hedging demands. In this section, we assume that there are $m=n+1$ independent sources of risk in the global economy and $n+1$ traded risky assets, the claims to country endowments (called equity claims). Securities markets are dynamically complete if the $n+1$ equity claims are non-redundant assets, so that the asset return diffusion matrix $\boldsymbol{\sigma}$ is invertible. To satisfy that condition, in the remainder of the section it will be assumed the preference matrix $\mathbf{A}$ is non-singular; for this condition to be satisfied, no two countries can have identical preferences.

This section illustrates that, under home bias in preferences, each country's endowment claim is a better hedge against changes in its domestic risk aversion. As a result, equity portfolios are home biased; in fact, it will be shown that equity portfolios are superbiased, in the Bennett and Young (1999) sense.

\subsection{Asset Prices}

The equilibrium price of the country $i$ endowment claim, expressed in units of the numeraire good is

$$
V_{t}^{i}=\frac{1}{\rho} \frac{\rho g_{t}^{i}+\varphi \bar{g}^{i}}{(\rho+\varphi) g_{t}^{0}} \widetilde{X}_{t}^{0}
$$

Note that it is increasing in the effective risk aversion of the demand for good $i, g^{i}$, and decreasing in the effective risk aversion of the demand for the numeraire good, $g^{0}$. 
We can understand changes in $V^{i}$ as a combination of valuation effects and terms of trade effects. The valuation effect regards fluctuations in the price-dividend ratio of equity $i$ :

$$
\frac{V_{t}^{i}}{\widetilde{X}_{t}^{i} Q_{t}^{i}}=\frac{1}{\rho}\left(\frac{\varphi}{\rho+\varphi} \frac{\bar{g}^{i}}{g_{t}^{i}}+\frac{\rho}{\rho+\varphi}\right)
$$

and depends solely on $g^{i}$, the effective risk aversion of the demand for good $i$. The terms of trade effect regards fluctuations in the numeraire price of good $i, Q^{i}$, which, as we have seen, is increasing in $g^{i}$ and decreasing in $g^{0}$. Notably - and in contrast to the closed economy benchmark - an increase in $g^{i}$ is not necessarily associated with a decrease of $V^{i}$ : although the valuation ratio declines, the dividends become more valuable due to the appreciation of good $i$.

\subsection{Equilibrium portfolios}

The remaining task is to determine the equilibrium country portfolios. The following proposition, proven in the Appendix, provides the answer.

Proposition 3 In equilibrium, each country $i$ holds a buy-and-hold risky portfolio that contains $\theta^{i, j}$ shares of the claim on the endowment of country $j$. The risky portfolio matrix $\boldsymbol{\Theta}$, defined as $\left[\theta_{i, j}\right]=\theta^{i-1, j-1}$, satisfies $\boldsymbol{\Theta}=\left(\mathbf{A}^{-1}\right)^{\top}$. Furthermore, no country holds any of the riskless asset. As a result:

(a) If $a^{i, i}-a^{i^{\prime}, i}>\sum_{s \neq i, i^{\prime}}\left|a^{i, s}-a^{i^{\prime}, s}\right|$ for all $i^{\prime} \neq i$ (weak home bias condition), country $i$ holds a home superbiased portfolio: $\theta^{i, i}>1$ and $\theta^{i, j}<0$ for at least one $j \neq i$.

(b) If $\frac{a^{i, i}}{a^{i, j}}-\frac{a^{i^{\prime}, i}}{a^{i^{\prime}, j}}>\sum_{s \neq i, i^{\prime}, j}\left|\frac{a^{i, s}}{a^{i, j}}-\frac{a^{i^{\prime}, s}}{a^{i^{\prime}, j}}\right|$ for all $i^{\prime} \neq i$ (strong home bias condition), country $i$ holds a home hyperbiased portfolio: $\theta^{i, i}>1$ and $\theta^{i, j}<0$ for all $j \neq i$.

The portfolio weights of country $i$ are:

$$
x_{t}^{i, j}=\frac{\theta^{i, j} V_{t}^{j}}{W_{t}^{i}}=\theta^{i, j} \frac{\rho g_{t}^{j}+\varphi \bar{g}^{j}}{\lambda^{i}\left(\rho G_{t}^{i}+\varphi \bar{G}\right)}
$$

Since no country holds the riskless asset, all equilibrium portfolios are equity-only portfolios. Furthermore, each country adopts a buy-and-hold strategy: it chooses a portfolio at $t=0$ and never reallocates. If preferences are weakly home biased, as described above, each country holds a superbiased portfolio: each country has a superlong position in its own claim, financed by short-selling at least one other country's claim. Furthermore, if preferences are strongly home biased, equilibrium country portfolios are hyperbiased: each country is superlong on its claim and short on the claims of all the other countries in the world. Although the number of shares in each country's portfolio is constant, the portfolio weight vector $\mathbf{x}_{t}^{i}$ is time-varying.

Since differences in equilibrium country portfolios are due to differences in the countries' hedging portfolios, we can easily infer that, under strong home bias, for any $i$, claim $i$ has a 
higher weight in the hedging portfolio of country $i$ than in any other country's hedging portfolio. Therefore, following the discussion in the previous section, claim $i$ is a better hedge against (changes in) the conditional risk aversion $G^{i}$ than against any other country's conditional risk aversion $G^{i^{\prime}}, i^{\prime} \neq i$. However, that does not necessarily mean that claim $i$ is the best hedge against $G^{i}$ across all available assets.

It is useful to contrast our economy with a benchmark economy that is characterized by absence of external habit formation, but is otherwise identical to our economy. In that case, as mentioned in a previous section, each country invests in the mean-variance optimal portfolio. However, it can be shown that if the available assets are the $n+1$ endowment claims, equilibrium asset prices are such that all claims have perfectly correlated returns in terms of the numeraire. Therefore, equilibrium country portfolios are indeterminate: the competitive equilibrium allocation can be achieved by any buy-and-hold portfolio $\boldsymbol{\theta}^{i}$ that satisfies

$$
\sum_{j=0}^{n}\left(\sum_{k=0}^{n} a^{k, j} \lambda^{k}\right) \theta^{i, j}=\lambda^{i}
$$

The aforementioned set of portfolios includes both the external habit equilibrium portfolio and the autarky portfolio. Since the autarky portfolio can generate the optimal allocation, asset trading is not necessary: countries can achieve optimality by trading only in the spot market for goods.

\subsection{External adjustment and home bias}

The net financial assets of country $i, N F A^{i}$, are defined as the difference between the country's foreign assets and foreign liabilities. Therefore, $N F A^{i}$ equal the difference between the financial wealth of country $i$ and the capitalized value of its future endowment, which represents the net position of the country with respect to the rest of the world:

$$
\begin{aligned}
N F A_{t}^{i} & =W_{t}^{i}-V_{t}^{i} \\
& =\frac{1}{\rho}\left(\rho\left(\lambda^{i} G_{t}^{i}-\sum_{k=0}^{n} a^{k, i} \lambda^{k} G_{t}^{k}\right)+\varphi \bar{G}\left(\lambda^{i}-\sum_{k=0}^{n} a^{k, i} \lambda^{k}\right)\right) \frac{\widetilde{X}_{t}^{0}}{(\rho+\varphi) g_{t}^{0}}
\end{aligned}
$$

It follows that $N F A^{i}$ is increasing in $G^{i}$ and decreasing in the risk aversion of all other countries $\left(G^{k}, k \neq i\right)$ : country $i$ hedges its exposure to the increase in its risk aversion by investing in a portfolio that generates a positive net financial position with respect to the rest of the world when $G^{i}$ increases and finances its elevated future consumption needs - which involve net imports for a number of subsequent years - by progressively drawing down its savings. As we have seen, this decrease in country $i$ net savings does not involve decreasing the holdings of the number of shares in country $i$ portfolio; rather, country $i$ net imports are financed by its 
portfolio dividends.

The static nature of countries' portfolios does not mean that equity home bias is constant; due to valuation effects, the home bias will be time-varying. I define the home bias measure for country $i$ as

$$
H B_{t}^{i}=x_{t}^{i, i}-b_{t}^{i}
$$

where $b_{t}^{i}$ is the benchmark weight of asset $i$, defined as the weight of the asset $i$ in the valueweighted global asset portfolio:

$$
b_{t}^{i} \equiv \frac{V_{t}^{i}}{\sum_{k=0}^{n} V_{t}^{k}}=\frac{\rho g_{t}^{i}+\varphi \bar{g}^{i}}{\sum_{k=0}^{n}\left(\rho g_{t}^{k}+\varphi \bar{g}^{k}\right)}
$$

Since both the portfolio share of home equity $x_{t}^{i, i}$ and the benchmark weight $b_{t}^{i}$ vary with time, the home bias measure $H B_{t}^{i}$ also varies with time. If preferences are home biased, the benchmark weight of asset $i, b_{t}^{i}$, is increasing in $G^{i}$ and decreasing in $G^{i^{\prime}}, i \neq i^{\prime}$, while $x_{t}^{i, i}$, the proportion of country $i$ portfolio invested in the home asset, is decreasing in $G^{i}$ and increasing in $G^{i^{\prime}}, i \neq i^{\prime}$. Thus, the home bias measure of country $i, H B_{t}^{i}$, is decreasing in country $i$ conditional risk aversion and increasing in the conditional risk aversion of all other countries.

\subsection{Intuition: the two-country case}

To better understand the intuition behind the aforementioned results, we can focus on the twocountry case. For easier interpretation of the results, I consider the symmetric home bias case, with the home bias parameter being $a>0.5$; the preference matrix is

$$
\mathbf{A}=\left[\begin{array}{cc}
a & 1-a \\
1-a & a
\end{array}\right]
$$

Thus, the equilibrium portfolio matrix is

$$
\boldsymbol{\Theta}=\left(\mathbf{A}^{-1}\right)^{\top}=\frac{1}{2 a-1}\left[\begin{array}{cc}
a & -(1-a) \\
-(1-a) & a
\end{array}\right]
$$

so the domestic country portfolio is comprised of $\theta^{0,0}=\frac{a}{2 a-1}>1$ shares of the domestic asset and $\theta^{0,1}=-\frac{1-a}{2 a-1}<0$ shares of the foreign asset.

To understand why each country biases its equity portfolio towards the home equity claim, we can consider the effects of an one-standard deviation negative domestic endowment shock (Figures 1, 2 and 3). ${ }^{14}$ Figure 1 presents the effects on endowment and consumption. Since

\footnotetext{
${ }^{14}$ I assume that both countries' initial conditional risk aversion is equal to its steady-state value $\left(G_{0}^{0}=G_{0}^{1}=\bar{G}\right)$.
} 
the negative domestic endowment shock (panel (a)) is a permanent shock, it entails a reduction of the steady-state level of domestic endowment (panel (b)). As a result of risk sharing, consumption growth experiences a negative shock in both countries (panel (c)). However, due to home bias in preferences and, hence, consumption, international risk sharing is imperfect: the domestic consumption growth shock is greater in magnitude and the steady-state level of domestic consumption is lower than that of foreign consumption (panel (d)). The adjustment to the new steady-state consumption levels does not happen instantaneously, but occurs gradually.

Figure 2 illustrates the adjustment process. To understand why adjustment is gradual and not instantaneous, we need to consider conditional risk aversion. Since conditional risk aversion is perfectly negatively correlated with consumption growth, both countries' risk aversion increases, but domestic risk aversion increases more; furthermore, in the absence of any future endowment (and, thus, consumption) shocks, both countries' risk aversion reverts to its steady-state level (panel (a)). Since the risk aversion shock is a temporary one, the two countries stagger their transition to their new steady-state consumption levels in order to minimize utility losses: during the adjustment period, domestic consumption is supported by net imports from the foreign country (panel (b)). To implement international risk sharing, the two countries hold portfolios that finance those international trade flows. Specifically, at the time of the negative shock, the domestic country portfolio is a better hedge against domestic endowment shocks than the foreign portfolio. As a result, the proportion of global wealth held by the domestic country increases (panel (c)) and domestic assets exceed foreign liabilities: the domestic country has positive net foreign assets (panel (d)). Thus, the stream of domestic net imports during the adjustment period is financed by gradually drawing down the domestic net foreign assets. The adjustment period ends when the domestic country has exhausted its net foreign assets, in which time the trading balance between the two countries is zero and consumption achieves its steady-state level in both countries.

Figure 3 presents the impact in asset prices and portfolios. Since domestic condition risk aversion increases more than foreign risk aversion, the effective conditional risk aversion of the demand for the domestic good, $g^{0}$, increases more than the effective risk aversion of the demand for the foreign good, $g^{1}$. Consequently, the price-dividend ratio of the domestic equity decreases more than the price-dividend ratio of the foreign equity (panel (a)), which constitutes a valuation effect. On the other hand, the numeraire price of the foreign good, $Q^{1}$, decreases (panel (b)). The terms of trade effect dominates the valuation effect, so domestic equity is a better hedge against adverse fluctuations of domestic risk aversion than foreign equity: $V^{1}$, the numeraire price of the foreign equity, decreases more than $V^{0}$, the numeraire price of the domestic equity (panel (c)). As a result, the benchmark weight of the domestic asset, $b^{0}$, increases and the benchmark weight of the foreign asset, $b_{1}$, decreases (panel $(\mathrm{d})$ ). Furthermore, the weight of domestic equity in the domestic portfolio $\left(x^{0,0}\right)$ decreases, while the weight of the foreign asset in the foreign portfolio $\left(x^{1,1}\right)$ decreases (panel (e)). Thus, the domestic agent invests a relatively 
low proportion of her wealth in the domestic asset, exactly when the domestic asset constitutes a relatively high proportion of the global portfolio. Those two effects reinforce each other, decreasing domestic portfolio home bias. Following the same analysis, foreign portfolio home bias increases (panel (f)).

Notably, (7) suggests that portfolio superbias is decreasing in preference home bias: as $a$ increases from 0.5 to 1 , the number of domestic (foreign) shares in the domestic portfolio decreases (increases), and vice versa for the foreign portfolio. The reason is that as preference home bias increases ( $a$ increases), each country's equity becomes a better hedge against increases in home risk aversion. Specifically, the disparity between the behavior of the domestic equity price $V^{0}$ and the foreign equity price $V^{1}$ is generated solely by the disparity in the behavior of $g^{0}$ and $g^{1}$, which is in increasing in preference home bias. The higher the preference home bias is, the more differently shocks in domestic and foreign risk aversion affect $g^{0}$ and $g^{1}$ and, thus, $V^{0}$ and $V^{1}$, enhancing the hedging properties of the two equity claims. On that other hand, as mentioned earlier, the wealth shares $\omega^{W, 0}$ and $\omega^{W, 1}$ do not depend on the preference matrix A. Thus, an increase in preference home bias does not affect the hedging demands of the two countries, but increase the hedging effectiveness of the two assets. As a result, each country needs a less home biased portfolio in order to be able to generate the same hedging outcome.

\subsubsection{Simulation}

To examine the quantitative aspects of the model, I simulate a two-country economy adopting the following simple specification for the two endowment processes:

$$
d \log \widetilde{X}_{t}^{0}=\mu d t+\sigma d B_{t}^{0}
$$

and

$$
d \log \widetilde{X}_{t}^{1}=\mu d t+\sigma d B_{t}^{1}
$$

For both goods, endowment growth has constant drift $\mu$ and constant volatility $\sigma$; endowment growth is not correlated across countries. The annualized parameter values used are reported in Table $1 .^{15}$ I consider the home bias parameter values of $a=0.51,0.7,0.9$ and 0.99 . I simulate 10,000 sample paths of the model economy, with each path consisting of 240 quarterly observations. Of the 240 observations, the first 40 (10 years) are discarded to reduce the dependence on initial conditions.

Tables 2, 3 and 4 present the properties of key moments in this economy. As Table 2 shows,

\footnotetext{
${ }^{15}$ The system is initialized at the steady state $\left(G_{0}^{0}=G_{0}^{1}=\bar{G}\right)$ and I adopt the normalization $\widetilde{X}_{0}^{0}=\widetilde{X}_{0}^{1}=1$. The mean and standard deviation of endowment growth are set equal to the corresponding moments of quarterly US endowment growth from 1975:Q1 to 2007:Q2, with endowment defined as the sum of consumption of non-durables and services and net exports. The habit parameters are those used in Menzly, Santos and Veronesi (2004), with the exception of $k$, which is set slightly lower.
} 
consumption growth volatility and numeraire excess returns have empirically plausible magnitudes for all home bias parameters. As preferences become more home biased, international risk sharing declines: the cross-country correlation of consumption growth rates declines, while real exchange rate volatility increases. As a result, each country bears more risk: inter alia, consumption growth volatility increases. The decline in international risk sharing is reflected in asset prices: equity excess returns increase and become more volatile and less internationally correlated. For all home bias parametrizations, the Sharpe ratio of domestic equity is higher than the Sharpe ratio of foreign equity, ${ }^{16}$ but only marginally so, while the two numeraire asset returns are very highly correlated.

Table 3 concerns the pricing of risk in the global economy. The first three rows present the means of the conditional prices of the three priced risk factors (aggregate wealth, domestic conditional risk aversion and foreign conditional risk aversion), denoted by $\lambda^{W^{A}}, \lambda^{G^{0}}$ and $\lambda^{G^{1}}$, respectively. The most highly priced risk factor is aggregate wealth: agents require that a unit loading on the aggregate wealth factor be compensated by an annualized risk premium of $3.5-4.5 \%$, depending on the degree of preference home bias. The compensation for exposure to fluctuations of either domestic or foreign conditional risk aversion is about (minus) $1 \%$ per year. ${ }^{17}$ It should be stressed that the three factors are not orthogonal to each other; rather, they are very highly correlated. As seen in Table 4, positive innovations in either domestic or foreign risk aversion are associated with negative innovations in aggregate wealth, due to valuation effects, while the innovations in the two countries' risk aversion processes are very highly correlated, as a result of risk sharing. The last six rows of Table 3 present the unconditional betas of the two country's equity claims with respect to the three risk factors. Domestic equity is a better hedge against adverse innovations in aggregate wealth. Importantly, each equity claim hedges its home risk aversion better than the other country's equity: domestic (foreign) equity hedges domestic (foreign) risk aversion fluctuations better than foreign (domestic) equity does.

Tables 5 and 6 report the equilibrium portfolios. I decompose the number of shares each agent holds into two components: the number of shares in the mean-variance portfolio and the number of shares in the agent's hedging portfolio. I also present the unconditional betas of the different portfolios. Notably, the mean-variance portfolio for both countries is highly leveraged, long on domestic equity and short on foreign equity: the two equity returns are very highly correlated, so mean-variance optimality entails holding a very leveraged position in the asset with the marginally higher Sharpe ratio (the domestic equity), financed by a short position in the asset with the lower Sharpe ratio (the foreign equity). On the other hand, both agents' hedging portfolios are long on the foreign asset and short on the domestic asset. However, the

\footnotetext{
${ }^{16}$ This is due to the fact that both returns are expressed in terms of the domestic good (which is the numeraire good), so the foreign asset return embeds terms of trade fluctuations that reduce its mean-variance attractiveness.

${ }^{17}$ The price of risk for $G^{0}$ and $G^{1}$ is negative, as a positive loading on those two factors indicates hedging against increases in risk aversion (and, thus, against increases in marginal utility).
} 
foreign hedging portfolio is more skewed toward the foreign asset than the domestic portfolio: the foreign hedging portfolio is more sensitive to fluctuations of domestic risk aversion and less sensitive to fluctuations of foreign risk aversion than the domestic portfolio, reflecting the difference in the hedging desires of the two agents. The skew towards the foreign asset in the foreign hedging portfolio is enough to reverse the skew towards the domestic asset in the meanvariance portfolio and, thus, the foreign portfolio ends up being home superbiased. On the other hand, the foreign asset skew in the domestic hedging portfolio is not enough to reverse the domestic asset skew of the mean-variance portfolio, so the domestic portfolio is superbiased towards the domestic asset.

\section{Conclusion}

This paper shows that external habit formation, coupled with home bias in preferences, can generate significant equity home bias, along with realistic asset pricing moments, in a frictionless economy populated by fully rational agents. The mechanism that generates equity portfolio home bias is novel: countries bias their portfolio towards the home asset due to their desire to hedge against adverse movements in their conditional risk aversion.

However, it is unlikely that time-varying risk aversion, generated by external habit formation, can fully explain the complex dynamics of portfolio choice in open economies. To wit, the model generates portfolio superbias, which is at variance with the data, indicating that other features of reality play a significant role in international portfolio choice. The extant international finance literature has pointed to many such features: frictions in the market for goods, asset market frictions and restrictions and informational differences across countries, as well as behavioral biases, may well cause first-order effects in the behavior of investors. More complex models that build on the success of the external habit formation model and extend it by adopting more complex - and more realistic - assumptions would likely enhance our understanding of portfolio home bias. By shifting attention from models that generate too little home bias to a model that generates too much home bias, the model underscores the importance of frictions that tend to decrease portfolio home bias (such as no short-selling restrictions), rather than frictions that tend to increase home bias, which have been the focus of the existing literature. 


\section{References}

[1] Adler, M. and B. Dumas, 1983, International Portfolio Choice and Corporation Finance: A Synthesis, Journal of Finance 38, 925-984.

[2] Aydemir, A. C., 2008, Risk Sharing and Counter-cyclical Variation in Market Correlations, Journal of Economic Dynamics and Control 32, 3084-3112.

[3] Bansal, R. and I. K. Shaliastovich, 2010, A Long-Run Risks Explanation of Predictability Puzzles in Bond and Currency Markets, Working paper, Duke University and the University of Pennsylvania.

[4] Baxter, M. and U. J. Jermann, 1997, The International Diversification Puzzle is Worse Than You Think, American Economic Review 87, 170-180.

[5] Baxter, M., U. J. Jermann and R. G. King, 1998, Nontraded Goods, Nontraded Factors and International Non-Diversification, Journal of International Economics 44, 211-229.

[6] Bekaert, G., 1996, The Time Variation of Risk and Return in Foreign Exchange Markets: A General Equilibrium Perspective, Review of Financial Studies 9, 427-470.

[7] Bekaert, G., E. Engstrom and Y. Xing, 2009, Risk, Uncertainty and Asset Prices, Journal of Financial Economics 91, 59-82.

[8] Bennett, J. A. and L. Young, 1999, International Stock Market Equilibrium with Heterogeneous Tastes, American Economic Review 89, 639-648.

[9] Black, F., 1974, International Capital Market Equilibrium with Investment Barriers, Journal of Financial Economics 1, 337-352.

[10] Brandt, M. W., J. H. Cochrane and P. Santa-Clara, 2006, International Risk Sharing Is Better Than You Think, or Exchange Rates are too Smooth, Journal of Monetary Economics $53,671-698$.

[11] Brennan, M. and H. Cao, 1997, International Portfolio Investment Flows, Journal of Finance 52, 1851-1880.

[12] Buraschi A. and A. Jiltsov, 2007, Habit Formation and Macroeconomic Models of the Term Structure of Interest Rates, Journal of Finance 62, 3009-3063.

[13] Campbell, J. Y. and J. H. Cochrane, 1999, By Force of Habit: A Consumption-Based Explanation of Aggregate Stock Market Behavior, Journal of Political Economy 107, 205251. 
[14] Coeurdacier, N., 2009, Do Trade Costs in Goods Market Lead to Home Bias in Equities?, Journal of International Economics 77, 86-100.

[15] Coeurdacier, N. and P. - O. Gourinchas, 2009, When Bonds Matter: Home Bias in Goods and Assets, Working paper, London Business School and UC Berkeley.

[16] Coeurdacier, N., R. Kollman and P. Martin, 2010, International Portfolios, Capital Accumulation and Foreign Assets Dynamics, Journal of International Economics 80, 100-112.

[17] Coeurdacier, N. and H. Rey, 2011, Home Bias in Open Economy Financial Macroeconomics, Working paper, Sciences Po and London Business School.

[18] Colacito R. and M. M. Croce, 2010a, Risks for the Long Run and the Real Exchange Rate, Working paper, University of North Carolina.

[19] Colacito R. and M. M. Croce, 2010b, Risk Sharing for the Long Run. The Gains from Financial Integration, Working paper, University of North Carolina.

[20] Cole H. L. and M. Obstfeld, 1991, Commodity Trade and International Risk Sharing: How Much Do Financial Markets Matter?, Journal of Monetary Economics 28, 3-24.

[21] Cooper, I. and E. Kaplanis, 1994, Home Bias in Equity Portfolios, Inflation Hedging and International Capital Market Equilibrium, Review of Financial Studies 7, 45-60.

[22] Dumas, B., K. K. Lewis and E. Osambela, 2011, Differences of Opinion and International Equity Markets, Working paper, INSEAD, University of Pennsylvania and Carnegie Mellon University.

[23] Errunza, V., 1983, Emerging Markets: A New Opportunity for Improving Global Portfolio Performance, Financial Analysts Journal 39, 51-58.

[24] Farhi E. and X. Gabaix, 2008, Rare Disasters and Exchange Rates, Working paper, Harvard University and NYU.

[25] French, K. R. and J. M. Poterba, 1991, Investor Diversification and International Equity Markets, American Economic Review 81, 222-226.

[26] Grubel, H., 1968, Internationally Diversified Portfolios: Welfare Gains and Capital Flows, American Economic Review 58, 1299-1314.

[27] Heathcote, J. and F. Perri, 2008, The International Diversification Puzzle is not as Bad as You Think, Working paper, Federal Reserve Board and University of Minnessota. 
[28] Jones, R. W., S. Marjit and T. Mitra, 1993, The Stolper-Samuelson Theorem: Links to Dominant Diagonals, in R. Becker, M. Boldrin, R. Jones and W. Thomson eds., General Equilibrium, Growth and Trade, Vol. 2, New York: Academic Press, 429-441.

[29] Julliard, C., 2002, The International Diversification Puzzle is not Worse Than You Think, Working paper, London School of Economics.

[30] Kang, J. - K. and R. Stulz, 1997, Why is there Home Bias? An Analysis of Foreign Equity Ownership in Japan, Journal of Financial Economics 46, 3-28.

[31] Karolyi, G. A. and R. M. Stulz, 2003, Are Assets Priced Locally or Globally?, in Constantinides, G., M. Harris and R. M. Stulz (eds.), The Handbook of the Economics of Finance, North Holland, 2003.

[32] Kollman, R., 2006a, A Dynamic Equilibrium Model of International Portfolio Holdings: Comment, Econometrica 74, 269-273.

[33] Kollman, R., 2006b, International Portfolio Equilibrium and the Current Account, CEPR Discussion Paper No. 5512.

[34] Lessard, D., 1973, World, National and Industry Factors in Equity Returns, Journal of Finance 29, 379-391.

[35] Levy, H. and M. Sarnat, 1970, International Diversification of Investment Portfolios, American Economic Review 60, 668-675.

[36] Lewis, K. K., 1999, Trying to Explain Home Bias in Equities and Consumption, Journal of Economic Literature 37, 571-608.

[37] Lucas, R. E., 1982, Interest Rates and Currency Prices in a Two-Country World, Journal of Monetary Economics 10, 335-359.

[38] Lustig, H. and A. Verdelhan, 2007, The Cross-Section of Foreign Currency Risk Premia and Consumption Growth Risk, American Economic Review 97, 89-117.

[39] Menzly, L., T. Santos and P. Veronesi, 2004, Understanding Predictability, Journal of Political Economy 112, 1-47.

[40] Mitra, T. and R. W. Jones, 1992, Factor Shares and the Chipman Condition, Working paper, University of Rochester.

[41] Moore, M. J. and M. J. Roche, 2006, Solving Exchange Rate Puzzles with neither Sticky Prices nor Trade Costs, Working paper, Queen's University Belfast and National University of Ireland. 
[42] Obstfeld, M. and K. Rogoff, 2000, The Six Major Puzzles in International Macroeconomics: Is There a Common Cause?", NBER Working Paper No. 7777.

[43] Pavlova, A. and R. Rigobon, 2007, Asset Prices and Exchange Rates, Review of Financial Studies 20, 1139-1180.

[44] Pesenti, P. and E. van Wincoop, Can Nontradeables Generate Substantial Home Bias?, Journal of Money, Credit and Banking 34, 25-50.

[45] Santos, T. and P. Veronesi, 2006, Habit Formation, the Cross Section of Stock Returns and the Cash-Flow Risk Puzzle, Working paper, Columbia University and University of Chicago.

[46] Sercu, P., 1980, A generalization of the International Asset Pricing Model, Revue de l'Association Francaise de Finance 1, 91-135.

[47] Serrat, A., 2001, A Dynamic Equilibrium Model of International Portfolio Holdings, Econometrica $69,1467-1489$.

[48] Shore, S. H. and J. S. White, 2006, External Habit Formation and the Home Bias Puzzle, Working paper, University of Pennsylvania and University of Illinois, Urbana-Champaign.

[49] Solnik, B., 1974a, Why not Diversify Internationally Rather Than Domestically?, Financial Analysts Journal 30, 48-54.

[50] Solnik, B., 1974b, An Equilibrium Model of the International Capital Market, Journal of Economic Theory 8, 500-524.

[51] Stathopoulos, A., 2011, Asset Prices and Risk Sharing in Open Economies, Working paper, University of Southern California.

[52] Stockman, A. C. and H. Dellas, 1989, International Portfolio Nondiversification and Exchange Rate Variability, Journal of International Economics 26, 271-289.

[53] Stulz, R., 1981a, On the Effects of Barriers to International Investment, Journal of Finance $36,923-934$.

[54] Stulz, R., 1981b, A Model of International Asset Pricing, Journal of Financial Economics $9,383-406$.

[55] Tesar, L. L., 1993, International Risk Sharing and Non-traded Goods, Journal of International Economics 35, 1803-1832.

[56] Tesar, L. L. and I. M. Werner, 1995, Home Bias and High Turnover, Journal of International Money and Finance 14, 467-492. 
[57] Uppal, R., 1993, A General Equilibrium Model of International Portfolio Choice, Journal of Finance 48, 529-553.

[58] van Nieuwerburgh, S. and L. Veldkamp, 2008, Information Immobility and the Home Bias Puzzle, Working paper, New York University.

[59] van Wincoop, E. and F. E. Warnock, 2010, Can trade costs in goods explain home bias in assets?, Journal of International Money and Finance 29,1108-1123.

[60] Verdelhan, A., 2010, A Habit-Based Explanation of the Exchange Rate Risk Premium, Journal of Finance 65, 123-146.

[61] Zapatero, F., 1995, Equilibrium Asset Prices and Exchange Rates, Journal of Economic Dynamics and Control 19, 787-811. 


\section{A Appendix}

\section{A.1 Equilibrium}

\section{A.1.1 Quantities and Prices}

The first order conditions (FOCs) of agent $i$ are:

$$
e^{-\rho t} a^{i} \frac{G_{t}^{i}}{X_{t}^{i, j}}=\frac{1}{\lambda^{i}} \frac{\Xi_{t}}{\Xi_{0}} Q_{t}^{j}, \text { for all } j
$$

where $\frac{1}{\lambda^{i}}$ is the Lagrange multiplier associated with the budget constraint of agent $i$ holding with equality.

In equilibrium, all goods markets clear:

$$
\sum_{k=0}^{n} X_{t}^{i, j}=\tilde{X}_{t}^{j}, \text { for all } j
$$

Combining the FOCs with the market clearing conditions, we get the equilibrium consumption allocation.

The numeraire state-price density, $\Xi$, is:

$$
\frac{\Xi_{t}}{\Xi_{0}}=e^{-\rho t} a^{0,0} \lambda^{0} \frac{G_{t}^{0}}{X_{t}^{0,0}}=e^{-\rho t} \frac{g_{t}^{0}}{\widetilde{X}_{t}^{0}}
$$

The numeraire state-price density is the discounted marginal utility of the numeraire good, which, due to the absence of frictions in international goods trade, is common across countries. As expected, the state-price density it is increasing in the effective risk aversion of the demand for the numeraire good $g_{t}^{0}$ and, thus, is increasing in all countries' conditional risk aversions. Furthermore, $\Xi_{t}$ is decreasing in $\widetilde{X}_{t}^{0}$ : the marginal utility of the numeraire good is proportional to its scarcity. The discounted marginal utility of good $j \neq 0$ (common across countries) is equal to

$$
\frac{\Xi_{t}}{\Xi_{0}} Q_{t}^{j}=e^{-\rho t} \frac{g_{t}^{j}}{\widetilde{X}_{t}^{j}}
$$

and reflects the scarcity of good $j$, as well as the effective risk aversion of the demand for good $j$.

The risk-free rate $r^{f}$ and the market price of risk $\boldsymbol{\eta}$ satisfy (4), so an application of Itô's lemma on (8) yields

$$
r_{t}^{f}=\rho+\mu_{t}^{0, X}+\varphi \sum_{k=0}^{n} \omega^{k, 0}\left(\frac{G_{t}^{k}-\bar{G}}{G_{t}^{k}}\right)+\sum_{k=0}^{n} \omega^{k, 0} \boldsymbol{\sigma}_{t}^{k, G \prime} \boldsymbol{\sigma}_{t}^{0, X}-\frac{1}{2} \boldsymbol{\sigma}_{t}^{0, X \prime} \boldsymbol{\sigma}_{t}^{0, X}
$$


and

$$
\boldsymbol{\eta}_{t}=\boldsymbol{\sigma}_{t}^{0, X}-\sum_{k=0}^{n} \omega^{k, 0} \boldsymbol{\sigma}_{t}^{k, G}
$$

To calculate the Lagrange multipliers $\frac{1}{\lambda^{i}}$, we substitute equilibrium quantities and prices in the static budget constraint of agent $i$ (holding with equality). After some algebra, we get:

$$
\lambda^{i}\left(\varphi \bar{G}+\rho G_{0}^{i}\right)=\sum_{k=0}^{n} a^{k, i} \lambda^{k}\left(\varphi \bar{G}+\rho G_{0}^{k}\right)
$$

This system of equations has solutions of the form

$$
\frac{\lambda^{i}}{\lambda^{0}}=b^{i} \frac{\varphi \bar{G}+\rho G_{0}^{0}}{\varphi \bar{G}+\rho G_{0}^{i}}
$$

where the vector $\mathbf{b}=\left[b^{1}, b^{2}, \ldots, b^{n}\right]^{\prime}$ is the unique solution of

$$
\mathbf{b}=\left[\begin{array}{cccc}
a^{0,1} & a^{1,1} & \ldots & a^{n, 1} \\
a^{0,2} & a^{1,2} & \ldots & a^{n, 2} \\
\ldots & \ldots & \ldots & \ldots \\
a^{0, n} & a^{1, n} & \ldots & a^{n, n}
\end{array}\right]\left[\begin{array}{c}
1 \\
\mathbf{b}
\end{array}\right]
$$

The budget constraint determines only the ratios $\frac{\lambda^{i}}{\lambda^{0}}$. However, note that, for $t=0,(8)$ gives:

$$
\widetilde{X}_{0}=\sum_{k=0}^{n} a^{k, 0} \lambda^{k} G_{0}^{k}
$$

Substituting for the $\lambda^{i}$, we can solve for $\lambda^{0}$ in terms of the known initial conditions $\widetilde{X}_{0}$ and $G_{0}^{i}$, $i=0,1, \ldots, n$ :

$$
\lambda^{0}=\frac{\frac{1}{\varphi \bar{G}+\rho G_{0}^{0}}}{\frac{a^{0,0} G_{0}^{0}}{\varphi \bar{G}+\rho G_{0}^{0}}+\sum_{k=1}^{n} \frac{a^{k, 0} b^{k} G_{0}^{k}}{\varphi \bar{G}+\rho G_{0}^{k}}} \widetilde{X}_{0}
$$

\section{A.1.2 Equilibrium consumption processes}

Since the vector of equilibrium consumption $C=\left[C^{0}, \ldots, C^{n}\right]^{\prime}$ is a function of family of the state variables $G^{i}$, which, in turn, are driven by consumption growth shocks, we need to solve for the corresponding fixed point that satisfies both the equilibrium consumption allocations and the law of motion for $G^{i}, i=0, \ldots, n$. By definition, we have:

$$
C^{i} \equiv\left(\prod_{j=0}^{n}\left(X^{i, j}\right)^{a^{i, j}}\right)
$$


so, applying Itô's lemma and equating the diffusion terms, we get after some algebra:

$$
\psi_{t}^{i, i} \boldsymbol{\sigma}_{t}^{i, C}+\sum_{i^{\prime} \neq i} \psi_{t}^{i, i^{\prime}} \boldsymbol{\sigma}_{t}^{i^{\prime}, C}=\sum_{j=0}^{n} a^{i, j} \boldsymbol{\sigma}_{t}^{j, X}
$$

where

$$
\begin{gathered}
\psi_{t}^{i, i} \equiv 1+\left(1-\sum_{j=0}^{n} \frac{a^{i, j} a^{i, j} \lambda^{i} G_{t}^{i}}{g_{t}^{j}}\right) \delta\left(\frac{G_{t}^{i}-l}{G_{t}^{i}}\right) \\
\psi_{t}^{i, i^{\prime}} \equiv-\left(\sum_{j=0}^{n} \frac{a^{i, j} a^{i^{\prime}, j} \lambda^{i^{\prime}} G_{t}^{i^{\prime}}}{g_{t}^{j}}\right) \delta\left(\frac{G_{t}^{i^{\prime}}-l}{G_{t}^{i^{\prime}}}\right)
\end{gathered}
$$

This is a system of $m(n+1)$ equations and an equal number of unknowns. We can rewrite this in compact form as:

$$
\Psi_{t} \boldsymbol{\sigma}_{t}^{C}=\mathbf{A} \boldsymbol{\sigma}_{t}^{X}
$$

where

$$
\Psi_{t}=\left[\psi_{i, j}\right]=\psi_{t}^{i-1, j-1}
$$

$\boldsymbol{\sigma}_{t}^{C}$ is the $(n+1) x m$ matrix

$$
\boldsymbol{\sigma}_{t}^{C}=\left[\begin{array}{c}
\boldsymbol{\sigma}_{t}^{0, C \prime} \\
\ldots \\
\boldsymbol{\sigma}_{t}^{n, C \prime}
\end{array}\right]
$$

and $\boldsymbol{\sigma}_{t}^{X}$ is the $(n+1) x m$ matrix

$$
\boldsymbol{\sigma}_{t}^{X}=\left[\begin{array}{c}
\boldsymbol{\sigma}_{t}^{0, X \prime} \\
\ldots \\
\boldsymbol{\sigma}_{t}^{n, X \prime}
\end{array}\right]
$$

It follows that the consumption growth conditional volatilities satisfy:

$$
\boldsymbol{\sigma}_{t}^{C}=\left(\Psi_{t}^{-1} \mathbf{A}\right) \boldsymbol{\sigma}_{t}^{X}
$$

\section{A.2 Proofs}

\section{Proof of Proposition 1}

The wealth of the agent $i$ satisfies:

$$
W_{t}^{i}=E_{t}\left[\int_{t}^{\infty} \frac{\Xi_{s}}{\Xi_{t}} C_{s}^{i} P_{s}^{i} d s\right]=\lambda^{i} \frac{1}{\rho} \frac{\rho G_{t}^{i}+\varphi \bar{G}}{(\rho+\varphi) g_{t}^{0}} \widetilde{X}_{t}^{0}=\lambda^{i} \frac{1}{\rho} \frac{\rho G_{t}^{i}+\varphi \bar{G}}{\rho+\varphi} e^{-\rho t} \frac{\Xi_{0}}{\Xi_{t}}
$$


so, applying Itô's lemma, we get

$$
\frac{d W_{t}^{i}}{W_{t}^{i}}=[\cdot] d t+\left(\boldsymbol{\eta}_{t}+\left(\frac{\rho G_{t}^{i}}{\rho G_{t}^{i}+\varphi \bar{G}}\right) \boldsymbol{\sigma}_{t}^{i, G}\right)^{\prime} \mathbf{d B}_{t}
$$

Considering the intertemporal budget constraint of the domestic agent:

$$
\frac{d W_{t}^{i}}{W_{t}^{i}}=\mathbf{x}_{t}^{i \prime}\left(\boldsymbol{\mu}_{t}^{e} d t+\boldsymbol{\sigma}_{t} \mathbf{d B}_{t}\right)+r_{t}^{f} d t-\frac{C_{t}^{i} P_{t}^{i}}{W_{t}^{i}} d t
$$

and matching diffusions, we get

$$
\mathbf{x}_{t}^{i \prime} \boldsymbol{\sigma}_{t}=\left(\boldsymbol{\eta}_{t}+\left(\frac{\rho G_{t}^{i}}{\rho G_{t}^{i}+\varphi \bar{G}}\right) \boldsymbol{\sigma}_{t}^{i, G}\right)^{\prime}
$$

Solving for the portfolio weights $\mathbf{x}_{t}$, we get:

$$
\mathbf{x}_{t}^{i}=\left(\boldsymbol{\sigma}_{t}^{\prime}\right)^{-1} \boldsymbol{\eta}_{t}+\left(\frac{\rho G_{t}^{i}}{\rho G_{t}^{i}+\varphi \bar{G}}\right)\left(\boldsymbol{\sigma}_{t}^{\prime}\right)^{-1} \boldsymbol{\sigma}_{t}^{i, G}
$$

Recall that $\boldsymbol{\eta}_{t}=\boldsymbol{\sigma}_{t}^{-1} \boldsymbol{\mu}_{t}^{e}$, so

$$
\mathbf{x}_{t}^{i}=\left(\boldsymbol{\sigma}_{t} \boldsymbol{\sigma}_{t}^{\prime}\right)^{-1} \boldsymbol{\mu}_{t}^{e}+\left(\frac{\rho G_{t}^{i}}{\rho G_{t}^{i}+\varphi \bar{G}}\right)\left(\boldsymbol{\sigma}_{t}^{\prime}\right)^{-1} \boldsymbol{\sigma}_{t}^{i, G}
$$

\section{Proof of Proposition 2}

Aggregate global wealth $W_{t}^{A}$ is defined as the discounted present value of the aggregate global endowment

$$
W_{t}^{A}=E_{t}\left[\int_{t}^{\infty} \Xi_{s} \Xi_{t}^{n} \sum_{k=0}^{n}\left(\widetilde{X}_{t}^{k} Q_{t}^{k}\right) d s\right]
$$

and, in equilibrium, is equal to the sum of the wealth of all individual countries

$$
W_{t}^{A}=E_{t}\left[\int_{t}^{\infty} \frac{\Xi_{s}}{\Xi_{t}} \sum_{k=0}^{n}\left(C_{s}^{k} P_{s}^{k}\right) d s\right]=\sum_{k=0}^{n} W_{t}^{k}
$$

due to the market clearing condition

$$
\sum_{k=0}^{n} \widetilde{X}_{t}^{k} Q_{t}^{k}=\sum_{k=0}^{n} C_{s}^{k} P_{s}^{k}
$$


Solving, we get:

$$
\begin{aligned}
W_{t}^{A} & =\frac{\tilde{X}_{t}^{0}}{\rho(\rho+\varphi) g_{t}^{0}} \sum_{k=0}^{n} \lambda^{k}\left(\rho G_{t}^{k}+\varphi \bar{G}\right) \\
& =e^{-\rho t} \frac{\Xi_{0}}{\Xi_{t}} \frac{\sum_{k=0}^{n} \lambda^{k}\left(\rho G_{t}^{k}+\varphi \bar{G}\right)}{\rho(\rho+\varphi)}
\end{aligned}
$$

so, applying Itô's lemma, we have:

$$
\frac{d W_{t}^{A}}{W_{t}^{A}}=[\cdot] d t-\frac{d \Xi_{t}}{\Xi_{t}}+\sum_{i=0}^{n}\left(\frac{\rho \lambda^{i} G_{t}^{i}}{\sum_{k=0}^{n} \lambda^{k}\left(\rho G_{t}^{k}+\varphi \bar{G}\right)}\right) \frac{d G_{t}^{i}}{G_{t}^{i}}
$$

or

$$
\frac{d \Xi_{t}}{\Xi_{t}}=[\cdot] d t-\frac{d W_{t}^{A}}{W_{t}^{A}}+\sum_{i=0}^{n}\left(\frac{\rho \lambda^{i} G_{t}^{i}}{\sum_{k=0}^{n} \lambda^{k}\left(\rho G_{t}^{k}+\varphi \bar{G}\right)}\right) \frac{d G_{t}^{i}}{G_{t}^{i}}
$$

The risk premium for any asset $s$ is given by:

$$
E_{t}\left(d R_{t}^{s, e}\right)=-E_{t}\left(d R_{t}^{s, e} \frac{d \Xi_{t}}{\Xi_{t}}\right)
$$

so, substituting for $\frac{d \Xi_{t}}{\Xi_{t}}$, we get the ICAPM reported in Proposition 2.

\section{Proof of Proposition 3}

The numeraire return of asset $i$ has diffusion process

$$
\boldsymbol{\sigma}_{t}^{i, R}=\sum_{k=0}^{n} \lambda^{k} G_{t}^{k} \frac{a^{k, i} \rho g_{t}^{0}-a^{k, 0}\left(\rho g_{t}^{i}+\varphi \bar{g}_{t}^{i}\right)}{g_{t}^{0}\left(\varphi \bar{g}_{t}^{i}+\rho g_{t}^{i}\right)} \boldsymbol{\sigma}_{t}^{k, G}+\boldsymbol{\sigma}_{t}^{0, X}
$$

so the asset diffusion matrix is

$$
\boldsymbol{\sigma}_{t}=\left[\begin{array}{c}
\boldsymbol{\sigma}_{t}^{0, R \prime} \\
\ldots \\
\boldsymbol{\sigma}_{t}^{n, R \prime}
\end{array}\right]
$$

If $\mathbf{A}$ is invertible, $\boldsymbol{\sigma}_{t}$ is also invertible, so the equilibrium portfolio of agent $i$ is unique and given by

$$
\mathbf{x}_{t}^{i}=\left(\boldsymbol{\sigma}_{t} \boldsymbol{\sigma}_{t}^{\prime}\right)^{-1} \boldsymbol{\mu}_{t}^{e}+\left(\frac{\rho G_{t}^{i}}{\rho G_{t}^{i}+\varphi \bar{G}}\right)\left(\boldsymbol{\sigma}_{t}^{\prime}\right)^{-1} \boldsymbol{\sigma}_{t}^{i, G}
$$


where

$$
\boldsymbol{\mu}_{t}^{e}=\boldsymbol{\sigma}_{t} \boldsymbol{\eta}_{t}
$$

We guess that the solution is a fixed portfolio that comprises of $\theta^{i, j}$ shares of asset $j$. If every agent has a fixed portfolio, there is no asset trade at any $t>0$, so the equilibrium portfolio of agent $i$ should finance her consumption expenditure at all times and states. Therefore, it must hold that:

$$
\sum_{j=0}^{n} \theta^{i, j} \widetilde{X}_{t}^{j} Q_{t}^{j}=C_{t}^{i} P_{t}^{i}
$$

or, after some algebra:

$$
\sum_{j=0}^{n} \sum_{k=0}^{n} \theta^{i, j} a^{k, j} \lambda^{k} G_{t}^{k}=\lambda^{i} G_{t}^{i}
$$

Since each country's conditional risk aversion is stochastic, the expression above holds almost surely if and only if

$$
\sum_{j=0}^{n} \theta^{i, j} a^{i, j}=1 \text { and } \sum_{j=0}^{n} \theta^{i, j} a^{k, j}=0 \text { for all } k \neq i
$$

or, using matrix notation:

$$
\mathbf{A} \Theta^{\top}=\mathbf{I}_{n+1}
$$

so, given that $\mathbf{A}$ is invertible, the fixed portfolios satisfy

$$
\boldsymbol{\Theta}=\left(\mathbf{A}^{\top}\right)^{-1}=\left(\mathbf{A}^{-1}\right)^{\top}
$$

Since the problem has a unique solution, the fixed portfolio solution is the only solution.

Following Bennett and Young (1999), we can recognize that (9) describes a problem with a Stolper-Samuelson structure. Thus, the results (a) and (b) in Proposition 4 follow directly from results (b) and (d) of Proposition 3 in Bennett and Young (1999), which, in turn, follow from Jones, Marjit and Mitra (1993) and Mitra and Jones (1992), respectively. 
Table 1

Calibration Parameters (annualized)

\begin{tabular}{|l|c|c|}
\hline \multicolumn{1}{|c|}{ Endowment parameter } & Symbol & Value \\
\hline Endowment growth rate & $\mu$ & 0.015 \\
\hline Endowment growth volatility & $\sigma$ & 0.015 \\
\hline \multicolumn{1}{|c|}{ Preference parameter } & Symbol & Value \\
\hline Subjective rate of time preference & $\rho$ & 0.04 \\
\hline Speed of $G$ mean reversion & $\varphi$ & 0.12 \\
\hline$G$ sensitivity to consumption growth shocks & $\delta$ & 79.39 \\
\hline Lower bound of $G$ & $l$ & 20 \\
\hline Steady-state value of $G$ & $\bar{G}$ & 34 \\
\hline
\end{tabular}


Table 2

Simulated moments: prices and quantities

\begin{tabular}{|c|c|c|c|c|}
\hline Moment & $a=0.51$ & $a=0.7$ & $a=0.9$ & $a=0.99$ \\
\hline \multicolumn{5}{|c|}{} \\
\hline Domestic consumption growth st. dev. & $1.06 \%$ & $1.07 \%$ & $1.12 \%$ & $1.31 \%$ \\
\hline Foreign consumption growth st. dev. & $1.06 \%$ & $1.07 \%$ & $1.12 \%$ & $1.31 \%$ \\
\hline Consumption growth corr. & 1.000 & 0.954 & 0.810 & 0.398 \\
\hline Exchange rate change st. dev. & $0.04 \%$ & $1.00 \%$ & $4.32 \%$ & $26.34 \%$ \\
\hline Domestic excess return mean & $4.81 \%$ & $4.82 \%$ & $4.83 \%$ & $5.45 \%$ \\
\hline Domestic excess return st. dev. & $18.66 \%$ & $18.66 \%$ & $18.71 \%$ & $19.97 \%$ \\
\hline Domestic Sharpe ratio & 0.270 & 0.270 & 0.270 & 0.284 \\
\hline Foreign excess return mean & $4.81 \%$ & $4.82 \%$ & $4.85 \%$ & $6.26 \%$ \\
\hline Foreign excess return st. dev. & $18.66 \%$ & $18.67 \%$ & $18.81 \%$ & $23.62 \%$ \\
\hline Foreign Sharpe ratio & 0.270 & 0.270 & 0.270 & 0.279 \\
\hline Excess return corr. & 1.000 & 1.000 & 0.999 & 0.949 \\
\hline
\end{tabular}

Simulated annualized moments. I simulate 10,000 sample paths of the model economy, with each path consisting of 240 quarterly observations. Of the 240 observations, the first 40 (10 years) are discarded to reduce the dependence on initial conditions. For each of the moments of interest, Table 3 presents the sample average across the 10,000 simulations. 
Table 3

Simulated moments: determinants of asset returns

\begin{tabular}{|c|c|c|c|c|}
\hline Moment & $a=0.51$ & $a=0.7$ & $a=0.9$ & $a=0.99$ \\
\hline \multicolumn{5}{|c|}{} \\
\hline$\lambda^{W^{A}}$ mean & $3.47 \%$ & $3.47 \%$ & $3.50 \%$ & $4.50 \%$ \\
\hline$\lambda^{G^{0}}$ mean & $-1.15 \%$ & $-1.15 \%$ & $-1.15 \%$ & $-1.34 \%$ \\
\hline$\lambda^{G^{1}}$ mean & $-1.15 \%$ & $-1.15 \%$ & $-1.15 \%$ & $-1.37 \%$ \\
\hline Domestic $\beta^{W^{A}}$ mean & 0.98 & 0.98 & 0.98 & 0.91 \\
\hline Foreign $\beta^{W^{A}}$ mean & 0.98 & 0.98 & 0.99 & 1.08 \\
\hline Domestic $\beta^{G^{0}}$ mean & -0.75 & -0.75 & -0.75 & -0.75 \\
\hline Foreign $\beta^{G^{0}}$ mean & -0.75 & -0.75 & -0.75 & -0.85 \\
\hline Domestic $\beta^{G^{1}}$ mean & -0.75 & -0.75 & -0.73 & -0.44 \\
\hline Foreign $\beta^{G^{1}}$ mean & -0.75 & -0.75 & -0.73 & -0.35 \\
\hline
\end{tabular}

All moments are annualized. 
Table 4

Correlation matrix of the innovations of priced factors

\begin{tabular}{|c|c|c|c|}
\hline Factor & $W^{A}$ & $G^{0}$ & $G^{1}$ \\
\hline$W^{A}$ & 1.00 & -0.98 & -0.98 \\
\hline$G^{0}$ & & 1.00 & 1.00 \\
\hline$G^{1}$ & & & 1.00 \\
\hline
\end{tabular}

$a=0.7$

\begin{tabular}{|c|c|c|c|}
\hline Factor & $W^{A}$ & $G^{0}$ & $G^{1}$ \\
\hline$W^{A}$ & 1.00 & -0.98 & -0.98 \\
\hline$G^{0}$ & & 1.00 & 1.00 \\
\hline$G^{1}$ & & & 1.00 \\
\hline
\end{tabular}

$a=0.9$

\begin{tabular}{|c|c|c|c|}
\hline Factor & $W^{A}$ & $G^{0}$ & $G^{1}$ \\
\hline$W^{A}$ & 1.00 & -0.98 & -0.96 \\
\hline$G^{0}$ & & 1.00 & 0.99 \\
\hline$G^{1}$ & & & 1.00 \\
\hline
\end{tabular}

$a=0.99$

\begin{tabular}{|c|c|c|c|}
\hline Factor & $W^{A}$ & $G^{0}$ & $G^{1}$ \\
\hline$W^{A}$ & 1.00 & -0.97 & -0.46 \\
\hline$G^{0}$ & & 1.00 & 0.61 \\
\hline$G^{1}$ & & & 1.00 \\
\hline
\end{tabular}

All moments are annualized. 
Table 5

Simulated moments: domestic portfolio

\begin{tabular}{|c|c|c|c|c|}
\hline Moment & $a=0.51$ & $a=0.7$ & $a=0.9$ & $a=0.99$ \\
\hline \multicolumn{5}{|c|}{ Total portfolio } \\
\hline$\theta_{1}$ & 25.50 & 1.75 & 1.13 & 1.01 \\
\hline$\theta_{2}$ & -24.50 & -0.75 & -0.13 & -0.01 \\
\hline$\beta^{W^{A}}$ & 0.98 & 0.98 & 0.98 & 0.91 \\
\hline$\beta^{G^{0}}$ & -0.75 & -0.75 & -0.75 & -0.75 \\
\hline$\beta^{G^{1}}$ & -0.75 & -0.74 & -0.73 & -0.44 \\
\hline \multicolumn{5}{|c|}{ Mean-variance portfolio } \\
\hline$\theta_{1}$ & 1577.51 & 4.65 & 1.64 & 1.29 \\
\hline$\theta_{2}$ & -1576.23 & -3.37 & -0.36 & -0.02 \\
\hline$\beta^{W^{A}}$ & 0.98 & 0.98 & 0.98 & 0.78 \\
\hline$\beta^{G^{0}}$ & -0.75 & -0.75 & -0.75 & -0.66 \\
\hline$\beta^{G^{1}}$ & -0.75 & -0.74 & -0.73 & -0.43 \\
\hline \multicolumn{5}{|c|}{ Hedging portfolio } \\
\hline$\theta_{1}$ & -1552.01 & -2.90 & -0.52 & -0.28 \\
\hline$\theta_{2}$ & 1551.73 & 2.62 & 0.23 & 0.01 \\
\hline$\beta^{W^{A}}$ & 0.98 & 0.98 & 0.99 & 1.20 \\
\hline$\beta^{G^{0}}$ & -0.75 & -0.75 & -0.75 & -0.94 \\
\hline$\beta^{G^{1}}$ & -0.75 & -0.74 & -0.73 & -0.37 \\
\hline
\end{tabular}


Table 6

Simulated moments: foreign portfolio

\begin{tabular}{|c|c|c|c|c|}
\hline Moments & $a=0.51$ & $a=0.7$ & $a=0.9$ & $a=0.99$ \\
\hline \multicolumn{5}{|c|}{ Total portfolio } \\
\hline$\theta_{1}$ & -24.50 & -0.75 & -0.13 & -0.01 \\
\hline$\theta_{2}$ & 25.50 & 1.75 & 1.13 & 1.01 \\
\hline$\beta^{W^{A}}$ & 0.98 & 0.98 & 0.99 & 1.08 \\
\hline$\beta^{G^{0}}$ & -0.75 & -0.75 & -0.75 & -0.85 \\
\hline$\beta^{G^{1}}$ & -0.75 & -0.74 & -0.73 & -0.35 \\
\hline \multicolumn{5}{|c|}{ Mean-variance portfolio } \\
\hline$\theta_{1}$ & 1577.52 & 4.65 & 1.64 & 1.30 \\
\hline$\theta_{2}$ & -1576.23 & -3.37 & -0.36 & -0.02 \\
\hline$\beta^{W^{A}}$ & 0.98 & 0.98 & 0.98 & 0.78 \\
\hline$\beta^{G^{0}}$ & -0.75 & -0.75 & -0.75 & -0.66 \\
\hline$\beta^{G^{1}}$ & -0.75 & -0.74 & -0.73 & -0.43 \\
\hline \multicolumn{5}{|c|}{ Hedging portfolio } \\
\hline$\theta_{1}$ & -1602.02 & -5.40 & -1.77 & -1.31 \\
\hline$\theta_{2}$ & 1601.73 & 5.12 & 1.48 & 1.03 \\
\hline$\beta^{W^{A}}$ & 0.98 & 0.98 & 1.00 & 1.37 \\
\hline$\beta^{G^{0}}$ & -0.75 & -0.75 & -0.76 & -1.04 \\
\hline$\beta^{G^{1}}$ & -0.75 & -0.74 & -0.73 & -0.27 \\
\hline
\end{tabular}


Figure 1

Impulse response functions: endowment and consumption
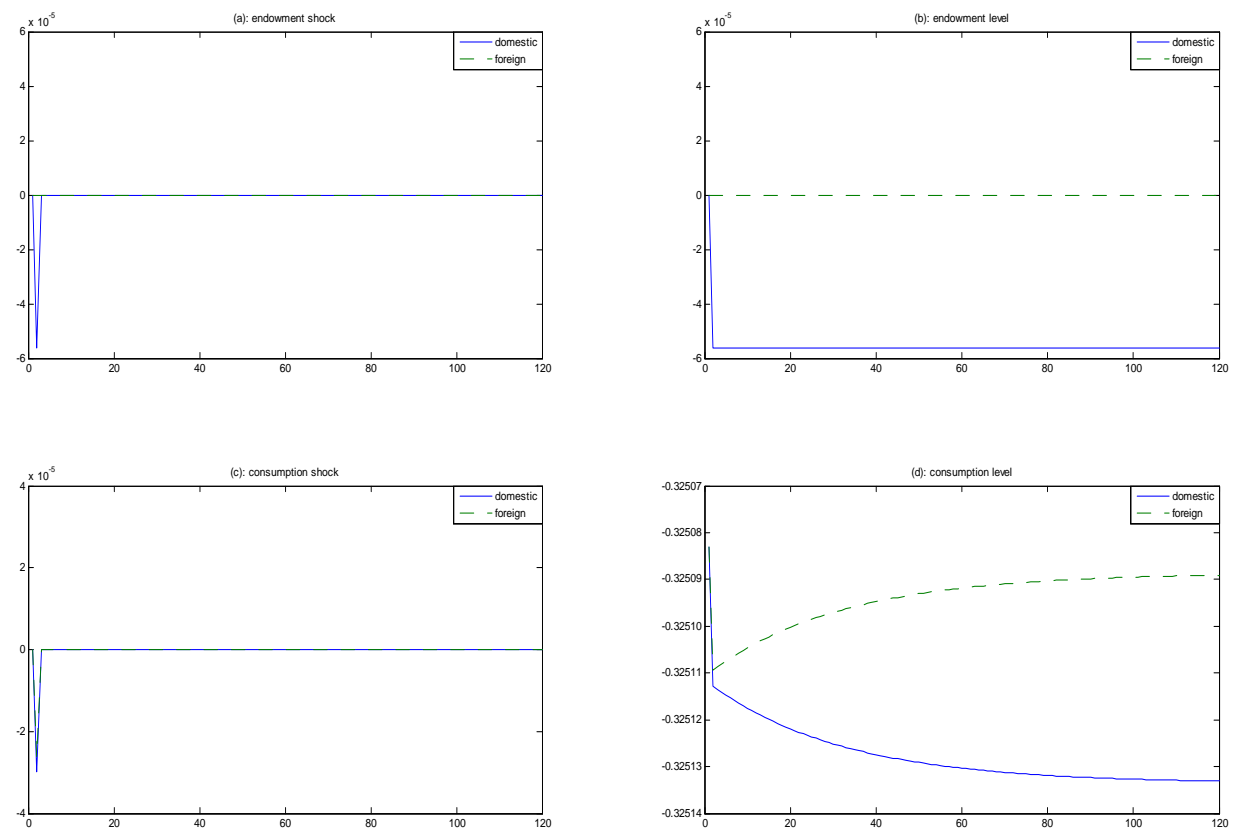

The horizontal axis measures time (in quarters) and the vertical axis the value of the moment of interest. 
Figure 2

Impulse response functions: wealth and the external sector
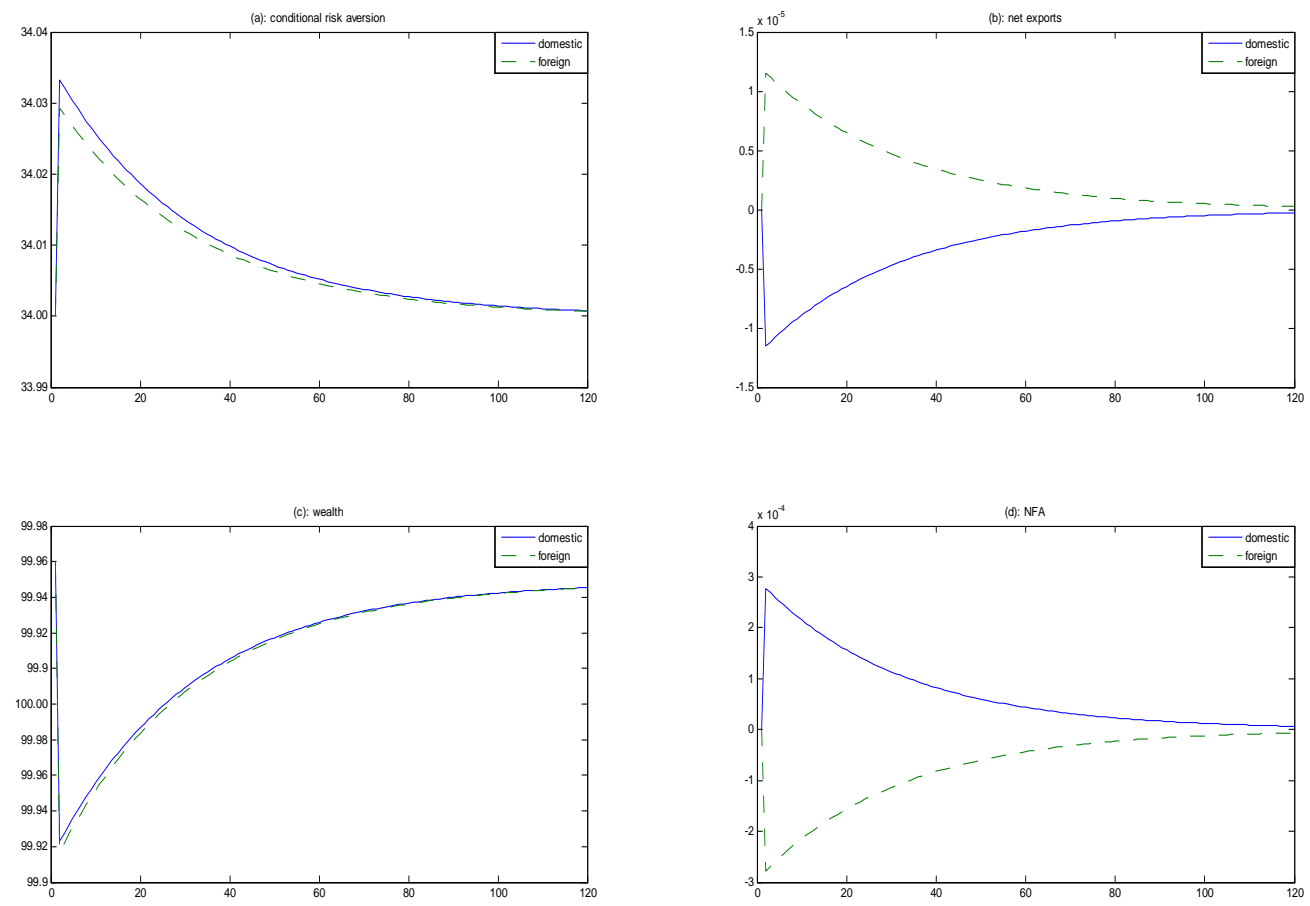

The horizontal axis measures time (in quarters) and the vertical axis the value of the moment of interest. 
Figure 3

Impulse response functions: asset prices and portfolios
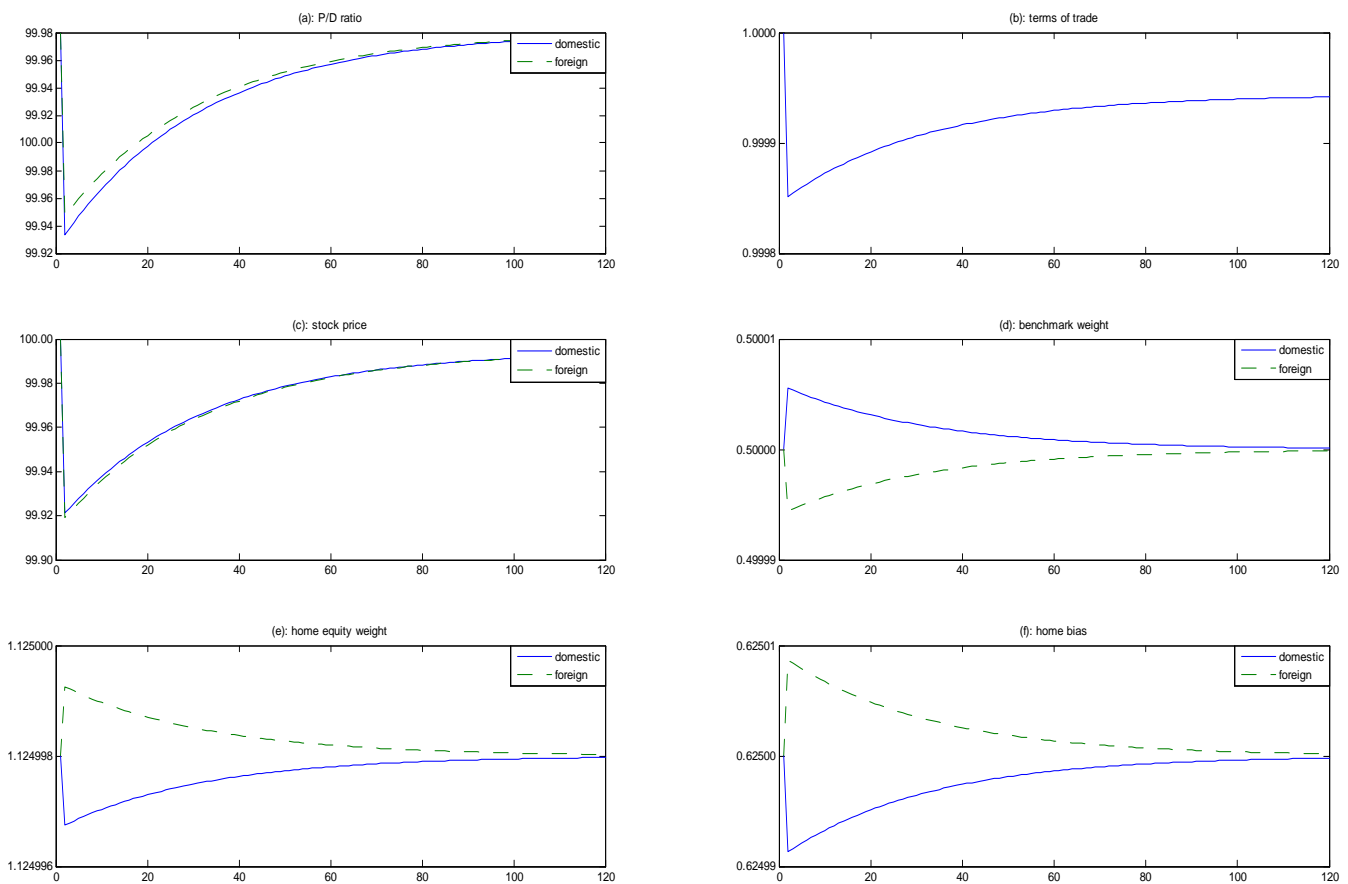

The horizontal axis measures time (in quarters) and the vertical axis the value of the moment of interest. 